NBER WORKING PAPER SERIES

\title{
DO ENVIRONMENTAL MARKETS IMPROVE ON OPEN ACCESS? EVIDENCE FROM CALIFORNIA GROUNDWATER RIGHTS
}

\author{
Andrew B. Ayres \\ Kyle C. Meng \\ Andrew J. Plantinga \\ Working Paper 26268 \\ http://www.nber.org/papers/w26268 \\ NATIONAL BUREAU OF ECONOMIC RESEARCH \\ 1050 Massachusetts Avenue \\ Cambridge, MA 02138 \\ September 2019, Revised March 2021
}

This paper was previously titled "Do Property Rights Alleviate the Problem of the Commons? Evidence from California Groundwater Rights." We acknowledge helpful comments from Max Au hammer, Spencer Banzhaf, Lint Barrage, Otavio Bartalotti, Youssef Benzarti, Chris Costello, Robert Heilmayr, Josh Hill, Matt Kahn, Bryan Leonard, Gary Libecap, Heather Royer, Randall Rucker, Doug Steigerwald, Walter Thurman, Gonzalo Vazquez-Bare, Randy Walsh, Paige Weber, Jinhua Zhao, and participants at the NBER EEE Summer Institute, and at other seminars and conferences. We thank Chris Free, Tracey Mangin, Gokce Sencan, and Vincent Thivierge for assistance with data. This research was funded by a grant through the UC Office of the President: MR-15-328650, Legal and Economic Data and Analysis of Environmental Markets and supported in part by PERC. The views expressed herein are those of the authors and do not necessarily reflect the views of the National Bureau of Economic Research.

NBER working papers are circulated for discussion and comment purposes. They have not been peer-reviewed or been subject to the review by the NBER Board of Directors that accompanies official NBER publications.

(C) 2019 by Andrew B. Ayres, Kyle C. Meng, and Andrew J. Plantinga. All rights reserved. Short sections of text, not to exceed two paragraphs, may be quoted without explicit permission provided that full credit, including $\odot$ notice, is given to the source. 
Do Environmental Markets Improve on Open Access? Evidence from California Groundwater

Rights

Andrew B. Ayres, Kyle C. Meng, and Andrew J. Plantinga

NBER Working Paper No. 26268

September 2019, Revised March 2021

JEL No. D23,P14,P48,Q15,Q25

\section{ABSTRACT}

Environmental markets are widely prescribed as an alternative to open-access regimes for natural resources. We develop a model of dynamic groundwater extraction to demonstrate how a spatial regression discontinuity design that exploits a spatially-incomplete market for groundwater rights recovers a lower bound on the market's net benefit. We apply this estimator to a major aquifer in water-scarce southern California and find that a groundwater market generated substantial net benefits, as capitalized in land values. Heterogeneity analyses point to gains arising in part from rights trading, enabling more efficient water use across sectors. Additional findings suggest the market increased groundwater levels.

Andrew B. Ayres

Public Policy Institute of California 500 Washington Street, Suite 600

San Francisco, CA 94111

andrew.ayres.225@gmail.com

Kyle C. Meng

Bren School of Environmental

Science and Management

Department of Economics

University of California, Santa Barbara

4416 Bren Hall

Santa Barbara, CA 93106

and NBER

kmeng@bren.ucsb.edu
Andrew J. Plantinga

Bren School of Environmental Science

and Management

University of California

Rm 3424

Santa Barbara, CA 93106

plantinga@bren.ucsb.edu 


\section{Introduction}

For almost two centuries, scholars have recognized that common-pool resources, if left under open-access conditions, tend to be used inefficiently (Lloyd, 1833; Coman, 1911; Gordon, 1954; Hardin, 1968; Ostrom, 1990). This issue is even more relevant today, with increasing concern over the status of natural resources such as fresh water, fisheries, and the global climate (Stavins, 2011).

In many settings, this "problem of the commons" arises because a market for property rights to the resource is missing (Coase, 1960). This insight underlies the modern framework for environmental markets - as suggested by Crocker (1966) and Dale (1968) and formalized by Montgomery (1972) - whereby a regulator sets a limit on total extraction, allocates extraction rights to users equaling this total, and oversees rights trading. ${ }^{1}$ Today, some form of environmental market covers 30\% of global fisheries (Costello et al., 2016), accounts for over $\$ 36$ billion in global ecosystem service payments (Salzman et al., 2018), and governs over $10 \%$ of global greenhouse gas (GHG) emissions (World Bank Group, 2020). ${ }^{2}$

The effectiveness of environmental markets, however, is predicated on a number of theoretical assumptions. A large literature has explored how the presence of market power (Hahn, 1984; Malueg, 1990), inadequate enforcement (Malik, 1990), transaction costs (Stavins, 1995), and other barriers (see Cropper and Oates (1992)) may adversely affect environmental market performance. Given how pervasive these features are in practice, ${ }^{3}$ it is an empirical question whether net benefits are generated when an environmental market replaces an open-access regime, and if so, why.

Researchers face three empirical challenges when quantifying the net benefit of an environmental market. First, one must track all agents that are directly affected by the regulated environmental good. This may be difficult for goods such as air quality where the (possibly unobserved) set of beneficiaries is highly dispersed. Second, one needs a measure of the good's economic value, which in the case of a stock resource such as groundwater or fish must reflect both current and future values. Third, environmental markets are often adopted when a resource is in a critical state of overextraction (Shertzer and Prager, 2006; Costello, Gaines and Lynham, 2008; Worm et al., 2009; Mangin et al., 2018). As such, simple comparisons between resources governed by a market and under open-access conditions may

\footnotetext{
${ }^{1}$ This additional structure overcomes some practical impediments to Coase's original formulation. In particular, having a regulator set a total extraction limit and manage rights trading can avoid transactions costs that may limit Coasian bargaining.

${ }^{2}$ In fisheries, such policies are often called rights-based management or individual transferable quotas. For air pollution and greenhouse gas emissions, they are typically known as cap-and-trade.

${ }^{3}$ Recent surveys of implemented environmental markets can be found in Tietenberg (2003), Freeman and Kolstad (2006), Goulder (2013), and Schmalensee and Stavins (2017).
} 
be confounded by differences in unobserved resource characteristics.

This paper studies a particular market for groundwater rights in southern California's Mojave Desert. ${ }^{4}$ We select this setting for two reasons. First, groundwater is a critical and increasingly scarce natural resource. It provides $50 \%$ of potable and $40 \%$ of irrigation water globally (Giordano, 2009; Aeschbach-Hertig and Gleeson, 2012), yet one-third of the world's largest aquifers are facing declining water levels (Richey et al., 2015). Moreover, groundwater scarcity is expected to worsen under demographic trends and anthropogenic climate change (Vörösmarty et al., 2000; Covich, 2009; McDonald et al., 2011; Prudhomme et al., 2014; Elliott et al., 2014; Ferguson et al., 2018). Second, our setting addresses the aforementioned empirical challenges. Land parcels within a known area of the Mojave Desert possess tradeable groundwater rights, the current and future values of which are capitalized in land values. Importantly, this market for groundwater rights does not cover the entire aquifer, allowing us to address endogeneity concerns by applying a spatial regression discontinuity (RD) design across the groundwater market boundary.

Our identification strategy leans heavily on renewable resource theory. The estimand of interest is the parcel-averaged difference in (potential) land prices between a groundwater market and an open-access regime. As in any potential outcomes framework, this difference cannot be estimated because land prices are not observed under both regimes. However, when a groundwater market does not spatially cover the entire aquifer, an opportunity arises for comparing land prices of parcels subject to the groundwater market with those of parcels under open access, all within the same observed setting. We develop a model of dynamic groundwater extraction to demonstrate that our estimand is ambiguously signed when the market for groundwater rights is spatially incomplete. A spatial RD design comparing land prices on either side of the groundwater market boundary removes potential endogeneity concerns as groundwater characteristics are likely continuous across the boundary. However, that same identifying assumption also removes changes in the water table, a potentially important consequence of the groundwater market, such that an RD estimate deviates from the estimand. We turn to our model to sign this bias, showing that the RD estimate yields a weak lower bound on the local average net benefit of a spatially-incomplete groundwater market, as well as for the population average net benefit under further assumptions.

Our empirical setting is the Mojave Desert, the driest desert in North America and yet a region that produces water-intensive crops. Mojave's verdant, irrigated farms in the midst of a barren desert have long been a poster child for inefficient water use. This stark contrast arises because underneath the Mojave Desert lies one of California's largest aquifers, which

\footnotetext{
${ }^{4}$ Interest in California water use in economics dates back at least to the article by Katherine Coman in the inaugural issue of the American Economic Review in 1911, revisited recently by Libecap (2011).
} 
has historically been extracted for agricultural use under open-access conditions. Agricultural irrigation led to severe groundwater depletion: between 1964 and 1990, the water table fell by 30 feet. Following failed attempts to limit pumping by creating a groundwater market in the 1960s and 1970s, a court process beginning in 1990 and finalized in 1996 created a system known as "adjudication" that imposes a total limit on groundwater pumping and allocates tradeable pumping rights to users within a particular spatial area. Importantly, this area - jointly determined by the boundaries of a pre-existing regulatory institution and a surface topographical feature - did not include all land parcels overlying the aquifer. This distinct spatial feature, together with a requirement that reported land values for agricultural parcels include the value of groundwater access, enables our RD estimator. ${ }^{5}$

We estimate that agricultural land values on the groundwater market side of the boundary are, on average, $220 \%$ higher than on the open access side. To validate the magnitude of this estimate, we show that it is less than an upper bound on the policy's net benefit: the total value of groundwater rights attached to adjudicated land parcels. We confirm that relevant covariates do not exhibit discontinuities at the boundary. We also demonstrate that our $\mathrm{RD}$ estimate is robust to alternative statistical modeling assumptions, bandwidth choices, potential error in land value assessments, how the boundary is defined, and other empirical concerns. Reassuringly, we do not detect RD effects using placebo boundaries falsely set within the groundwater market and open access areas. Using earlier land value data, we also fail to detect statistically significant RD estimates prior to the 1990s. In particular, the point estimate using 1976-1979 land values is 37\% of the estimate using post-1996 values. Given earlier failed attempts at establishing a similar groundwater market, a non-zero effect prior to the 1990s may reflect anticipation of an eventual groundwater market.

One potential explanation for our large RD estimate is that groundwater trading provides agricultural landowners the opportunity to capitalize on water's market value. For the Mojave aquifer, higher water values likely come from municipalities, particularly in the southern, more urban, areas overlying the aquifer. Indeed, heterogeneity analysis reveals a substantially higher RD estimate in the southern part of the aquifer compared to the north. This suggests that the ability to trade groundwater rights enhances land values by reallocating water away from water-intensive agriculture and towards meeting growing urban demand. ${ }^{6}$ Accounting for these heterogeneous effects and further assuming that unobserved charac-

\footnotetext{
${ }^{5}$ Groundwater rights have also been introduced elsewhere in California, and in total twenty-six basins have well-defined rights. Twenty of those basins have rights defined volumetrically, and trading is allowed in 19 of those. These 19 systems represent $4 \%$ of California's aquifers. However, the spatially-incomplete nature of the Mojave groundwater market, combined with rights trading, is unique in California.

${ }^{6}$ While our RD design prohibits us from exactly isolating the gains from groundwater trading, a backof-the-envelope calculation suggests that at most $39 \%$ of the net benefit can be attributed to trading.
} 
teristics are uncorrelated with distance to the boundary, we calculate that the groundwater market produced an aggregate net benefit of $\$ 350$ million (in 2015 dollars) for agricultural parcels, or a $40 \%$ increase in aggregate land value.

Our RD approach has two primary drawbacks. First, by measuring effects at the groundwater market boundary, our estimate does not capture potential benefits from higher groundwater levels under adjudication relative to the open access counterfactual. Instead, we turn to three additional pieces of evidence, all of which point towards increased groundwater levels: (i) we detect a positive trend break in average groundwater levels when the adjudication's pumping restrictions began for most users, (ii) we detect an RD jump in groundwater well drilling for open access parcels beginning at that same moment, consistent with increased groundwater under adjudication that spills over into open access areas, and (iii) we document that prices for groundwater rights have been consistently positive, which our theory shows is a sufficient condition for increased groundwater levels under adjudication relative to open access. The second limitation of our RD approach is that we cannot apply it to urban areas because they obtain water from municipal water systems, not local groundwater pumping. We extend our theory to show how data on aggregate urban water allocation and consumption combine to produce a back-of-the-envelope aggregate net benefit of $\$ 72-131$ million (in 2015 dollars) for urban areas. Altogether, the aggregate net benefit to agricultural and urban areas of the groundwater market is $\$ 422-481$ million. In contrast, the initial setup cost of the groundwater market during the 1990s was $\$ 40$ million (in 2015 dollars) (Figueroa, 2001).

This paper contributes to a recent literature using quasi-experimental techniques to understand the consequences of environmental markets. Studies of air pollution and greenhouse gas markets typically examine only regulatory costs (Petrick and Wagner, 2014; Calel and Dechezleprêtre, 2016; Meng, 2017; Calel, 2020) or benefits (Fowlie, Holland and Mansur, 2012; Deschenes, Greenstone and Shapiro, 2017; Hernandez-Cortes and Meng, 2020), rarely both. A larger literature exists for fisheries, reflecting the many instances of market-based management in that domain. These papers have found that rights-based management tends to reduce effort (Hsueh, 2017; Costello and Grainger, 2018; Isaksen and Richter, 2018), distribute effort more evenly across time (Birkenbach, Kaczan and Smith, 2017); and increase resource levels (Costello, Gaines and Lynham, 2008), efficiency (Grafton et al., 2011), and revenues (Scheld, Anderson and Uchida, 2012). ${ }^{7}$ For groundwater in particular, Drysdale and Hendricks (2018) and McLaughlin (2020) find reduced water use and higher groundwater levels, respectively, following the introduction of a water market. These outcomes, however, do not fully capture current and future net benefits of an environmental market. In our

\footnotetext{
${ }^{7}$ In another quasi-experimental study, Kroetz, Sanchirico and Lew (2015) examine how fishing permit prices diverge following the imposition of trading restrictions.
} 
setting, the value of groundwater access is bundled together with the value of a land parcel. As such, we are able to follow the Ricardian tradition by studying land prices that capture the current and future net benefit of a groundwater market.

Another related literature in development economics and economic history employs quasiexperimental approaches to study the consequences of stronger property rights for land, through, for example, more secure land title (Besley, 1995; Besley and Burgess, 2000; Banerjee, Gertler and Ghatak, 2002; Field, 2007; Galiani and Schargrodsky, 2010), lower enforcement costs (Hornbeck, 2010; Libecap and Lueck, 2011), and enhanced access rights (Iwanowsky, 2019). In these settings, land - the resource of interest - was privatized to a certain degree prior to treatment. A test of the consequences of introducing property rights requires a resource that was initially held in common. Our setting satisfies this requirement. ${ }^{8}$

Finally, our study informs the increasing need for groundwater management, particularly under anthropogenic climate change. For California, groundwater pumping - which historically provides one-half of the State's fresh water - has long been unsustainably extracted, with recent consequences especially acute during a prolonged drought (California Dept. of Water Res., 2015). In response, California passed the Sustainable Groundwater Management Act (SGMA), an unprecedented law requiring users of overextracted aquifers to adopt stringent management plans. Groundwater markets are considered a key policy instrument under SGMA (Aladjem and Sunding, 2015; Babbitt and Brozovic, 2017; Green Nylen and Doremus, 2017). ${ }^{9}$

The paper is structured as follows: Section 2 provides background on the Mojave aquifer and its spatially-incomplete market for groundwater rights. Section 3 introduces a dynamic model of groundwater extraction under open access and incomplete groundwater market regimes, which informs our empirical strategy in Section 4. Section 5 details data sources. Section 6 presents our main RD results, robustness checks, and heterogeneity analyses. Section 7 quantifies the aggregate net benefit for agricultural and urban areas and presents further evidence that the market has increased groundwater levels. Section 8 concludes.

\section{Background}

The Mojave Desert, located northeast of Los Angeles in southern California's San Bernardino County, is the driest desert in North America, receiving on average less than two inches of

\footnotetext{
${ }^{8}$ Note that in our setting landowners have rights to land, but groundwater use is still initially under open access.

${ }^{9}$ Surface water trading has also received renewed interest. Hagerty (2019) demonstrates potentially large gains from surface water trading in California. Rafey (2020) quantifies the gains from trade from observed surface water trading in southeastern Australia.
} 
rainfall annually. Yet, farmers in the Mojave Desert have historically produced alfalfa, pistachios, and stone fruits, all highly water-intensive crops. This production is possible, in part, because beneath this desert lies one of California's ten largest groundwater resources, which has historically been extracted for agricultural use under open access conditions. ${ }^{10}$

In recent decades, open-access pumping has led to a dramatic drop in the aquifer's water table. Figure 1 plots the average depth from surface to the water table across monitoring wells in the Mojave Desert: between 1964 and 1990, the water table fell by 30 feet. From 1966 to 1976, there was an initial, but failed, attempt on the part of the regional water regulator, the Mojave Water Agency, to allocate water rights through a system known as "adjudication." Discussions about adjudication continued throughout the 1970s and 1980s, culminating in a new adjudication lawsuit in 1990. In 1993, an agreement comprising $75 \%$ of groundwater users was reached. In 1996, the local court sanctioned an agreement that applied to nearly all users.

Adjudication has two components. First, water users received individual, perpetual annual groundwater pumping rights defined as their proportion of average annual pumping during the 1986-1990 base period. To stabilize groundwater levels, the aggregate annual allowable pumping across the aquifer ramps down over time. Each year, a perpetual right holder is able to pump an amount equal to their right, scaled back proportionally by the degree of aggregate rampdown. Second, users can buy or sell "paper" groundwater rights, either through annual leases or transfers of perpetual rights. These are paper rights in the sense that users do not transfer physical water. Instead, they exchange pumping rights with any other user (i.e., agricultural landowner or municipality), who also overlies the groundwater resource. Transfer of rights to users not overlying the resource would require physically transporting pumped water outside the basin and is prohibited. The resulting water market enables users to reap any allocative efficiency gains arising from the sale of rights to other users. This is an important change from the prior open access regime, in which users do not own rights to the water and, thus, can only pump water for own use. ${ }^{11}$

\footnotetext{
${ }^{10}$ Ostrom (2008) defines an open access resource as "a common-pool resource that anybody can enter and/or harvest." This definition is a reasonable approximation of the Mojave aquifer prior to adjudication. For overlying agricultural users, California law requires groundwater use to be "reasonable and beneficial." In practice, this criteria has historically allowed de facto open access as there has been unrestricted groundwater pumping for agricultural use in arid regions. Those without overlying land parcels, including municipalities but potentially any other user as well, were also able to access the aquifer, with the caveat that their rights had lower priority than those of overlying users. While not exactly matching a textbook definition of pure open access, we think open access remains the best description of the overall regime governing groundwater use prior to adjudication.

${ }^{11}$ In other settings, there may be a less formal arrangement involving local management of groundwater resources by a limited group of users, typically referred to as Groundwater Management Districts (GMDs) (Edwards, 2016). Local resource management is common in fisheries, referred to as territorial user rights fisheries (TURFs), and the subject of a large theoretical and empirical literature (Janmaat, 2005; Sampson
} 
Figure 1: Depth to groundwater before and after adjudication

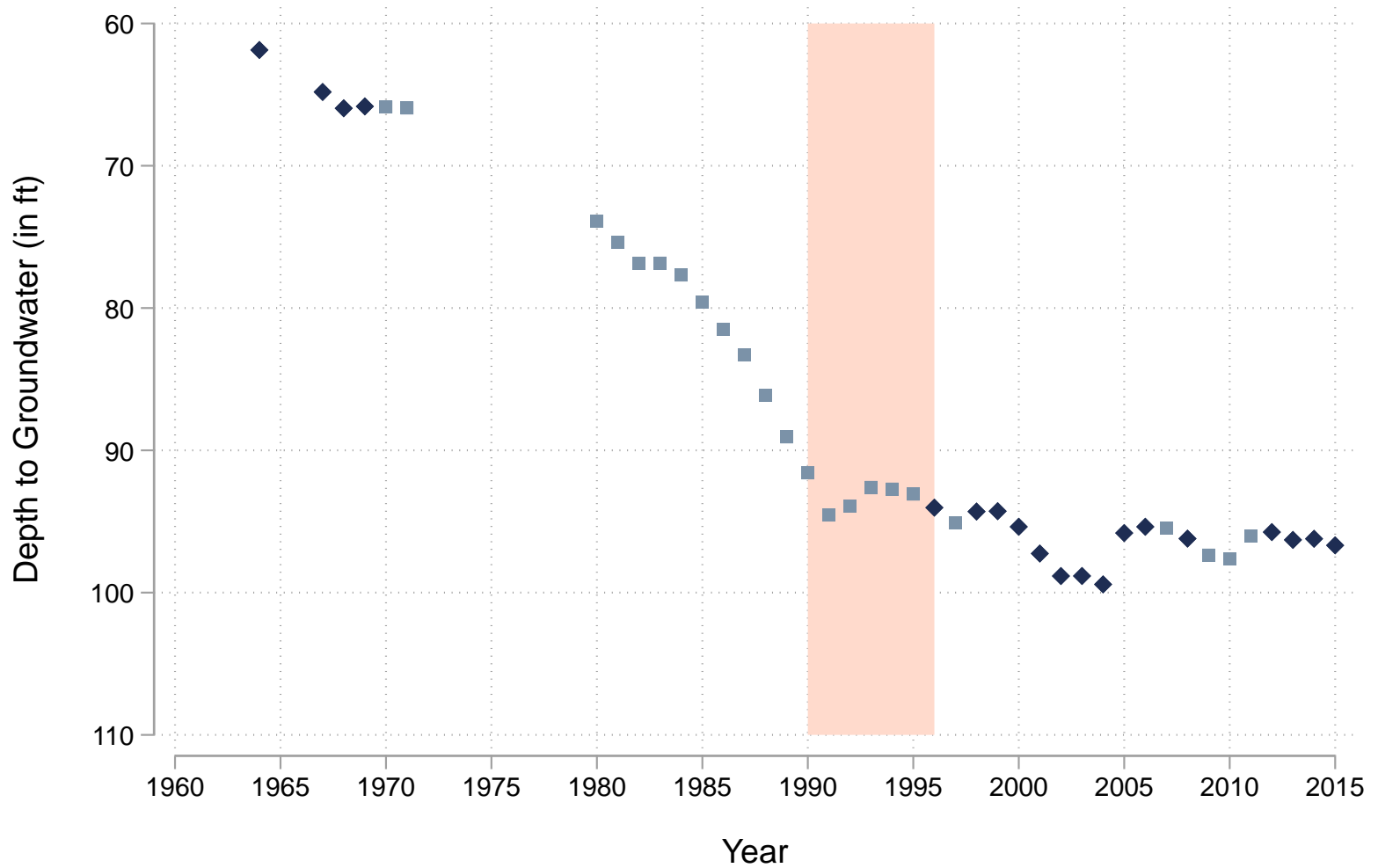

Notes: Vertical axis shows average distance (in feet) to water table across monitoring wells in the Mojave Desert. Horizontal axis indicates years. Dark blue diamonds indicate years where there is data for all monitoring wells. Light blue squares indicate years where missing data from one or more monitoring wells is linearly interpolated. Orange-shaded area marks the period from 1990 when the initial adjudication lawsuit was filed to 1996 when the final adjudication court ruling was issued. Data from the U.S. Geological Survey (USGS).

Adjudication also brought an added benefit to urban areas, where residents access groundwater through municipal water systems and not via their own pumping. Whereas agricultural landowners extracted under unrestricted open access prior to adjudication and thus were presumably at a private optimum, municipalities were previously restricted as they had lower priority access, entitling them to extract groundwater only beyond what was needed to satisfy agricultural demands. By redefining groundwater rights and introducing the ability to trade, adjudication elevated the rights of municipalities - and by extension urban residents - to be on par with agricultural rights, thus lifting restrictions and allowing for expanded pumping.

Despite these advantages, several features of the Mojave adjudication system deviate from a textbook optimal policy. First, it is unclear whether simply stabilizing the water level at its pre-adjudication level corresponds to an optimal water table height. Second, in addition and Sanchirico, 2019). 
to the prohibition on physical water transfers out of the basin, limits are also placed on water right trading across space and time. Landowners can only trade groundwater rights with overlying landowners or municipalities within the same subarea of the groundwater resource. Depending on how much these subareas are hydraulically connected, inefficiencies may arise from having separate groundwater markets. Likewise, water rights can only be banked one year ahead and cannot be borrowed from the future, which limits intertemporal smoothing of water consumption.

The most notable feature of the Mojave adjudication that deviates from an ideal groundwater market is that rights were not assigned over the entire spatial extent of the groundwater resource. Figure 2 illustrates the spatial boundary of the adjudication system (shown by purple and red lines) and the subsurface extent of the entire hydraulically-connected Mojave groundwater system (in blue shading), which we henceforth refer to simply as the Mojave aquifer. ${ }^{12}$ Observe that the spatial footprint of the adjudication system and Mojave aquifer areas do not perfectly overlap, so that some areas overlying the aquifer fall under adjudication (i.e., blue areas within the purple and red box) while others remain under open access (i.e., blue areas outside the purple and red box).

It is important to clarify how the adjudication boundary was drawn. Specifically, it is the spatial intersection of two regions: the jurisdictional area of the pre-existing Mojave Water Agency (shown by red line segments) and the physical surface drainage area of the Mojave River (shown by purple line segments). The straight-line boundaries of the Mojave Water Agency, formed in 1960 with largely unchanged boundaries since then, are based on the regular grid lines imposed by the Public Land Survey System from the 18th century and thus likely unrelated to subsurface groundwater characteristics. Likewise, the drainage extent of the Mojave River, which is determined by surface topographical features, is also plausibly exogenous to groundwater characteristics. ${ }^{13}$

A spatially-incomplete groundwater market, coupled with knowledge of how its boundary was drawn, provides an opportunity to apply a spatial RD design. Before we do so, it is instructive to explore what existing data indicate regarding the net benefit of the Mojave adjudication system. Figure 1 shows that groundwater levels indeed began to stabilize in the

\footnotetext{
${ }^{12}$ The key to defining the spatial extent of the relevant groundwater resource is hydraulic connectivity such that extraction in one location can affect the water table in other locations. The blue area in Figure 2 shows the hydraulically connected groundwater resources in the study area, as confirmed by hydrologists at the Mojave Water Agency. State and federal agencies may define multiple administrative "basins" in the region that need not be hydraulically independent. For example, the blue area in Figure 2 consists of several basins defined by California's Department of Water Resources that are largely hydraulically connected.

${ }^{13}$ As robustness checks, we test whether potentially relevant surface topographical features vary smoothly across the boundary. We also examine whether parcels near these two boundary definitions exhibit different $\mathrm{RD}$ estimates.
} 


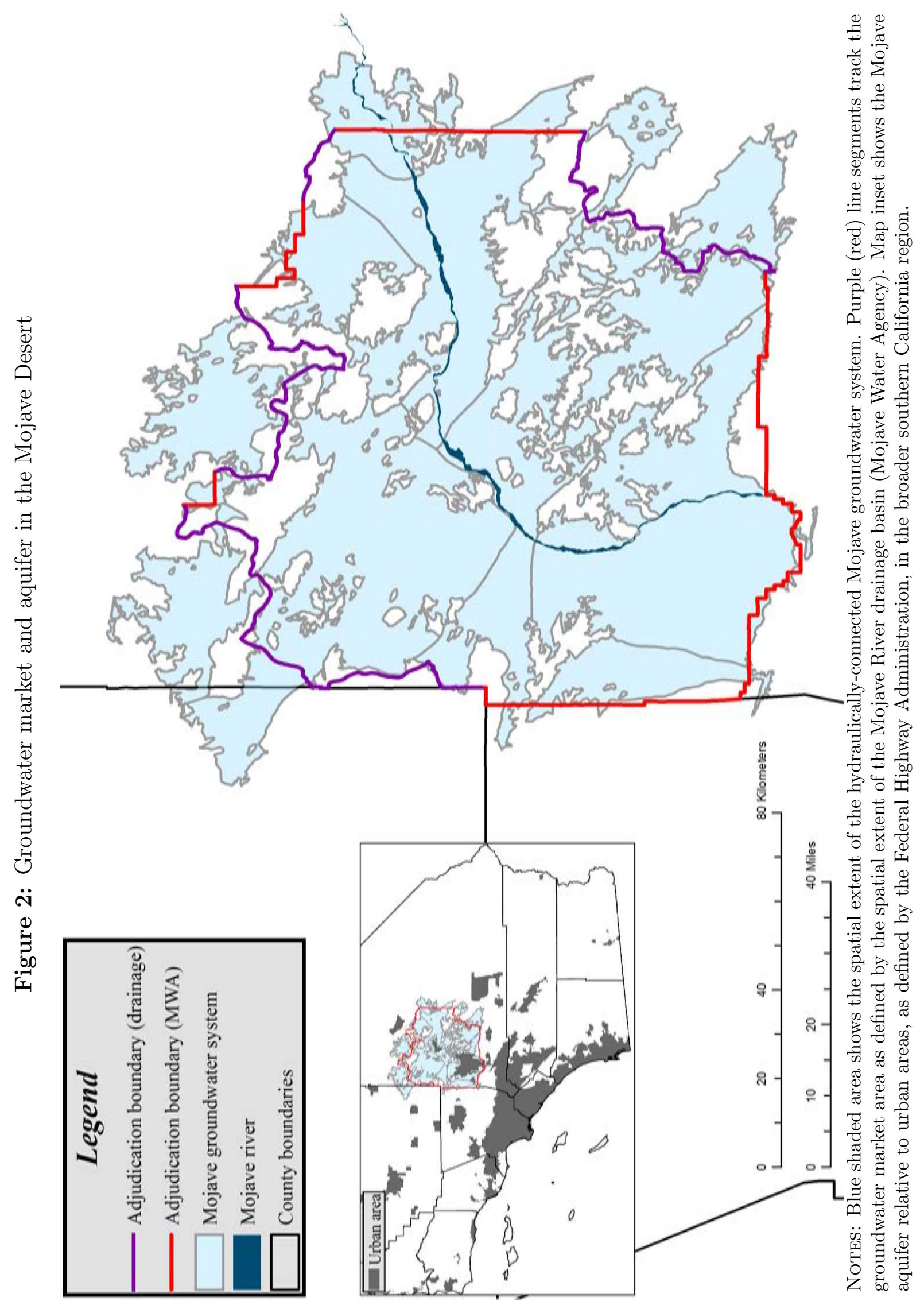


1990s. However, stabilized water levels alone do not imply positive net benefits for landowners under adjudication since pumping restrictions may be costly and transaction costs large. Furthermore, as our theory will show, stabilized water levels are also consistent with continued open access conditions that had yet to reach a steady state prior to adjudication. Trends in agricultural activity are also inconclusive. Figure B.1 shows that agricultural revenue in the Mojave Desert declined after adjudication was finalized. However, agricultural revenue does not capture possible gains from the reallocation of water to other sectors (e.g., urban water use), and thus does not provide a clear indication that adjudication benefited landowners.

Alternatively, one can follow the Ricardian tradition and examine land prices. This is possible in our data setting because the value of groundwater access in San Bernardino County is bundled together with the value of a land parcel. As such, land prices reflect the present discounted value of rental streams from both land and water assets. ${ }^{14}$ For open-access parcels, land prices capture the value of unrestricted groundwater pumping for own use. For parcels under adjudication, land prices reflect the cost of restricted groundwater pumping, as well as the benefits of a higher groundwater level and the potential gains from trading pumping rights. We now turn to a theoretical model of dynamic groundwater extraction to formalize what drives these land prices and how they relate to our empirical strategy.

\section{Theory}

This section develops a model of dynamic groundwater extraction for the Mojave aquifer. Recognizing that the Mojave adjudication regime deviates in practice along several dimensions from an optimal policy, we explicitly avoid characterizing optimality and instead consider a model that closely mirrors the policy's objective to stabilize water levels using spatially-incomplete groundwater rights. ${ }^{15}$ In particular, to replicate observed falling groundwater water levels prior to adjudication, as shown in Figure 1, we begin with all land parcels over the aquifer extracting groundwater under open access but without having yet reached a steady state. We then model land prices dynamics under counterfactual and factual regimes for the period after adjudication is introduced. In the first (counterfactual) regime, we model land price dynamics had open access conditions continued for all parcels over the aquifer. In the second (factual) regime, we model land price dynamics following the

\footnotetext{
${ }^{14}$ Land prices, however, do not capture the one-time sunk costs of setting up the adjudication system.

${ }^{15}$ An optimal policy will always do at least as well as open access. To be useful for empirical testing, our model must leave open the question of whether spatially-incomplete tradeable groundwater rights yield net benefits.
} 
introduction of adjudication's system of spatially-incomplete tradeable groundwater rights. ${ }^{16}$

Our theory generates several predictions that are used for interpreting our spatial RD estimator, presented in Section 4. First, we show that the difference in land prices between the two regimes, our estimand of interest, is of ambiguous sign. Intuitively, this is because relative to open access, adjudication imposes the cost of restricted pumping but also generates benefits from a higher water table and the ability to trade groundwater rights. Next, we demonstrate that a spatial RD estimator comparing parcels under adjudication and open access at the adjudication boundary produces a lower bound for the estimand at the boundary. This is because a spatial RD estimator, by design, omits differences in water table height, thus excluding the benefit of a higher water table due to adjudication. Finally, because water table levels are lower at the boundary than in the interior of the adjudication area, the RD estimator is also a lower bound on the estimand in the interior.

Throughout this section, we focus on agricultural parcels for which groundwater is "appurtenant," or tied, to the overlying land surface. This implies that water access is determined by local groundwater levels, which facilities our spatial RD design in Section 4. In contrast, urban areas receive piped water from municipal water systems whose groundwater access is determined regionally and thus cannot be examined with a spatial RD approach. We return to a discussion of net benefits for urban areas in Section 7.1.

\subsection{Setup}

There are $N$ identical agricultural landowners, each of whom has a land parcel that overlies $1 / N$ of the area of the aquifer. Instantaneous profits are given by $\pi(w, h)$ where $w$ is the pumping rate and $h$ is the water table height, measured as the vertical distance from the bottom of the aquifer to the water level. $\pi(w, h)$ is assumed to be concave and singled-peaked in $w$, increasing in $h$, and $\pi_{w h}>0$ since raising the water table height reduces the cost of pumping, making the marginal unit of water more profitable. The initial height of the water table is $h_{0}$ and the instantaneous rate of change in the water table height is $\dot{h}(t)$, where $t$ is time. After the initial period, dynamics of $h$ differ depending on whether the aquifer is under full open access or incomplete tradeable groundwater rights, as we discuss below.

\footnotetext{
${ }^{16} \mathrm{~A}$ comparison of land prices under the two regimes is valid only if the initial groundwater level is the same in both cases, implying that our theory must necessarily be dynamic in order to characterize adjustments to the steady states under open access and incomplete tradeable rights.
} 


\section{$3.2 \quad$ Full open access}

Under full open access, profit-maximizing landowners ignore any effects of their pumping on the water table, ${ }^{17}$ solving at each instant in time:

$$
\max _{w} \pi(w, h)
$$

The first-order condition $\frac{\partial \pi}{\partial w}=0$ defines $w^{a}(h)$, the pumping rate as a function of the height of the water table (the 'a' indicates full open access). Using Cramer's rule, $\frac{d w^{a}}{d h}=-\frac{\pi_{w h}}{\pi_{w w}}>0$, by the concavity of the profit identity, $\pi_{w w}<0$, and $\pi_{w h}>0$. Pumping rates under open access increase with the height of the water table.

Transition and steady state. Under open access, all users pump at the same rate and so the water table height is the same for all landowners. It evolves according to:

$$
\dot{h}^{a}(t)=R-N w^{a}(h(t))
$$

where $R$ is natural recharge and $N w^{a}(h(t))$ is aggregate pumping. ${ }^{18}$ Consistent with Figure 1 , we assume that the aquifer is out of steady state initially and that aggregate pumping $N w^{a}\left(h_{0}\right)$ exceeds recharge. By equation (2), this results in a declining water table. However, the drop in the water table height causes the open-access pumping rate to fall, by Cramer's rule. A steady state is reached when pumping is equal to recharge. ${ }^{19}$ The steady-state is defined as $\bar{h}^{a}$ such that $\dot{h}^{a}=R-N \bar{w}^{a}=0$, where $\bar{w}^{a}=w^{a}\left(\bar{h}^{a}\right)=R / N$.

The dynamics of the full open access system are illustrated in panel (a) of Figure 3. For a given value of $h$, the pumping rate is $w^{a}(h)$. Thus, any $w \neq w^{a}(h)$ moves immediately to the $\dot{w}=0$ locus defined by $w^{a}(h)$. From there, the dynamics of the system are governed by equation 2. The blue line in Figure 3 shows the transition to the steady state from the initial height of $h_{0}>\bar{h}^{a}$. When $h<\bar{h}^{a}$, the pumping rate and the water table height increase until the steady state is reached. In summary, under the full open access regime, we have $h_{0} \geq h^{a}(t) \geq \bar{h}^{a}$ and $w^{a}\left(h_{0}\right) \geq w^{a}\left(h^{a}(t)\right) \geq \bar{w}^{a}$ for $t \geq 0$.

Land price. Under perfect competition, the price of a land parcel is equal to the present discounted value of the infinite stream of profits. Thus, the full open access land price is

\footnotetext{
${ }^{17}$ Our open access model is a limiting case of uncoordinated spatial ownership (Kaffine and Costello, 2011), where each user has exclusive access to the water beneath their property, but pumping by other landowners gives rise to a stock externality.

${ }^{18}$ The volume of the aquifer is normalized to one so that volumetric variables, $R$ and $w$, are conformable with $h$.

${ }^{19}$ To ensure the steady state occurs at a strictly positive value of $h$, we assume $w^{a}(0)<R / N$. This assumption is justified for the Mojave aquifer given evidence of extremely deep aquifers in the region that go far beyond the depth of existing wells (Kang and Jackson, 2016; Perrone and Jasechko, 2019).
} 
given by:

$$
V^{a}=\int_{0}^{\infty} \pi\left(w^{a}(s), h^{a}(s)\right) e^{-\delta s} d s
$$

where $\delta$ is the discount rate and the time interval covers both the transition period and the steady state.

Figure 3: Phase plane diagrams of full open access and spatially-incomplete rights regimes

(a) Full open access

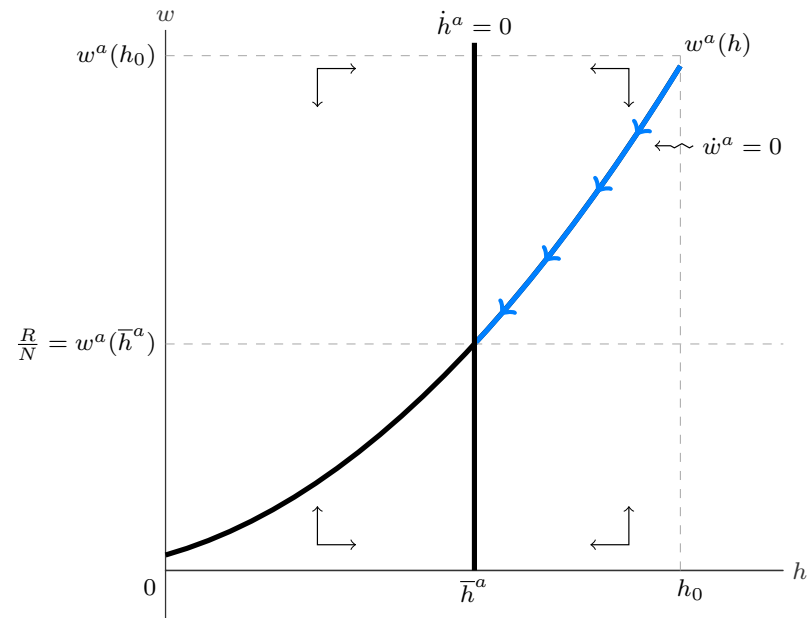

(b) Spatially-incomplete rights

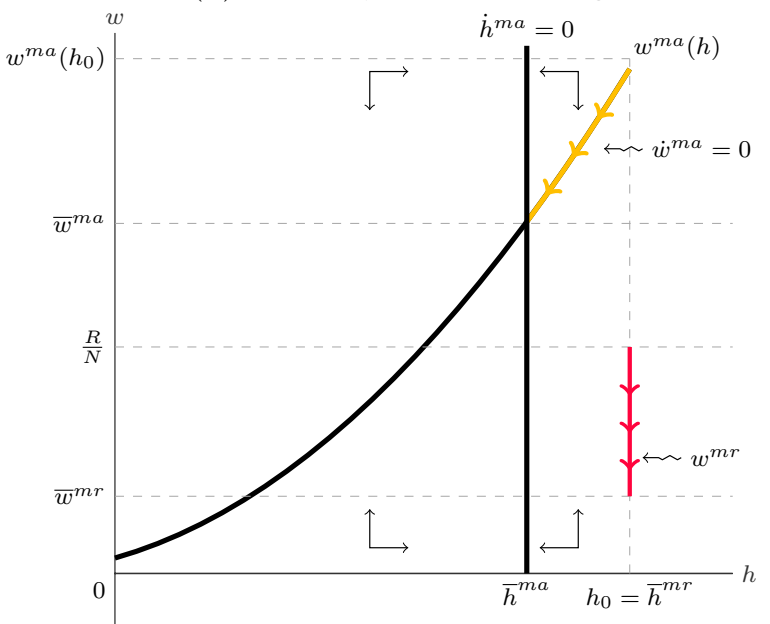

Notes: Figures illustrate the transition to the steady state for the full open access and adjudication's incomplete groundwater rights regimes starting from an initial water table height $h_{0}$. The directionals in each isosector apply to the open access users and are described in the text. The blue line in panel (a) is the transition path to the steady state at $\bar{h}^{a}$ and $w^{a}\left(\bar{h}^{a}\right)$ for open access users under the full open access regime. Under the adjudication regime, shown in panel (b), a representative open access parcel follows the orange line to the steady state at $h=\bar{h}^{m a}$ and $w=\bar{w}^{m a}$. A representative parcel with groundwater rights follows the red line with a constant stabilization target of $\bar{h}^{m r}$ and an exogenous pumping rate (determined by the regulator) that reaches a steady state at $w=\bar{w}^{m r}$.

\subsection{Spatially-incomplete groundwater rights}

Property rights are introduced to stabilize the water table at $h_{0}$, preventing the draw down of the aquifer that occurs under open access. If all $N$ landowners were under the property rights regime, the regulator would simply assign individual pumping rights equal to $R / N$. If users pump their full allocation, then by equation (2), the water table remains at its initial level $h_{0}$. In the steady state, the same volume of water is pumped as under the open access regime, but because $h_{0}>\bar{h}^{a}$, profits are higher than under open access (Gisser and Sanchez, 1980). The steady state is more complicated when property rights are incompletely assigned 
over the aquifer because users can pump at different rates. ${ }^{20}$

We examine this setting by modeling the two components of the Mojave adjudication regime: a restriction on pumping to stabilize water levels and tradeable property rights to pump groundwater. First, we characterize how pumping restrictions allow for stabilization of the water table. We then show how the market value of tradeable pumping rights is capitalized into land prices.

Under incomplete rights, only a share of the $N$ landowners hold property rights, with the rest of the landowners remaining under open access. Define $\alpha \in[0,1]$ as the share of open access landowners. We assume that all landowners under the property rights regime (indicated by ' $\mathrm{mr}$ ' where ' $\mathrm{m}$ ' denotes the incomplete, or mixed, regime and ' $\mathrm{r}$ ' indicates users with rights) hold rights to an endowment of water $w^{e}$, whereas open access users (indicated by 'ma') are unconstrained. Open access users continue to solve the profit maximization problem in 1, however, rights holders now solve:

$$
\max _{w} \pi(w, h) \quad \text { s.t. } \quad w \leq w^{e}
$$

Assuming $w>0$, the solution to equation (4) satisfies the first-order condition $\frac{\partial \pi}{\partial w}=\lambda^{m r}$ where $\lambda^{m r}$ is the shadow value on the constraint. The complementary slackness condition is $\lambda^{m r}\left(w-w^{e}\right)=0$, which says that at the optimum either the constraint binds or the shadow value of water equals zero (or both). The solution to equation (4) is denoted $w^{m r}$ and defined as the post-trading volume of water pumped by landowners in the adjudication area and applied to their land. For now, we assume that the endowments $w^{e}$ are the same for all landowners in the adjudication area, which implies no trading among agricultural users. ${ }^{21}$ We will relax this assumption below. Given the intent to prevent further groundwater drawdown under open access, the constraint in equation (4) binds and, thus, $w^{m r}=w^{e}$ for all rights holders.

To simplify the analysis, we focus on two representative users, one within the adjudication area with water table $h^{m r}$ and the other in the open access area with water table $h^{m a}$. The dynamics of the water table are described by a variant of equation $(2):^{22}$

$$
\begin{aligned}
& \dot{h}^{m a}=\alpha R+\theta\left(h^{m r}-h^{m a}\right)-\alpha N w^{a}\left(h^{m a}\right) \\
& \dot{h}^{m r}=(1-\alpha) R+\theta\left(h^{m a}-h^{m r}\right)-(1-\alpha) N w^{m r}
\end{aligned}
$$

\footnotetext{
${ }^{20}$ See Costello, Quérou and Tomini (2015) for a comparison of open access, incomplete property rights, and complete property rights regimes.

${ }^{21}$ Because landowners are identical in all respects, shadow values are equal at the initial endowment and there are no gains from trade.

${ }^{22}$ We suppress time arguments except when it is necessary to clarify a variable's dependence on time.
} 
where it is assumed that recharge occurs uniformly throughout the aquifer. ${ }^{23}$ Due to gravity, differences in the water table height produce a flow of water, dictated by $\theta \in[0,1]$, from one area to another.

Stabilization and transition. We assume that the goal of property rights is to stabilize the aquifer within the adjudication area at $\bar{h}^{m r}=h_{0}$ by imposing the pumping limit $w^{m r}(t)$. That is, the pumping limit is set in each period to achieve:

$$
\dot{h}^{m r}=(1-\alpha) R+\theta\left(h^{m a}(t)-\bar{h}^{m r}\right)-(1-\alpha) N w^{m r}(t)=0
$$

Although the water table is stabilized in the adjudication area, it continues to be drawn down in the open access area. Consider $\dot{h}^{m a}$ at $t=0$ :

$$
\dot{h}^{m a}=\alpha R+\theta\left(\bar{h}^{m r}-h^{m a}\right)-\alpha N w^{a}\left(h^{m a}\right)=\alpha R-\alpha N w^{a}\left(h_{0}\right)
$$

where $\bar{h}^{m r}=h^{m a}=h_{0}$. As under full open access, open access users under incomplete rights pump more than recharge at $h_{0}$ and $\dot{h}^{m a}<0$. The pumping rate by open access users depends only on the water table height according to $w^{m a}=w^{a}\left(h^{m a}\right)$, as in the full open access case. The dynamics of the incomplete rights system is illustrated in panel (b) of Figure 3, where the orange line depicts the transition to the steady state for open access users. ${ }^{24}$ Although the same trajectory is followed as under full open access, there is a positive flow of water to the open access area $\left(\bar{h}^{m r}-h^{m a}>0\right.$ for $\left.t>0\right)$, which slows the decline in $h^{m a}$ relative to the full open access case (we prove this result in this next section).

In order to keep $\bar{h}^{m r}$ at $h_{0}, w^{m r}(t)$ must fall over time by equation 7 . Solving for $w^{m r}(t)$ in equation 7 and taking the time derivative yields $\dot{w}^{m r}=\frac{\theta}{(1-\alpha) N} \dot{h}^{m a}<0$. The transition path for the pumping rate in the adjudication area is depicted by the red line in panel (b) of Figure 3. At $t=0, w^{m r}=R / N$, which is established from equation 7 and the fact that $\bar{h}^{m r}=h^{m a}$ at $t=0$. The pumping limit $w^{m r}(t)$ declines until steady states are reached in both areas, which we solve for next.

Steady states. Setting $\dot{h}^{m a}=0$ in equation 5 and substituting $\bar{h}^{m r}$, we define the following relationship between steady-state water table heights:

$$
\bar{h}^{m r}=\bar{h}^{m a}+\frac{\alpha}{\theta}\left(N w^{a}\left(\bar{h}^{m a}\right)-R\right)
$$

The assumption in footnote 24 implies that for any stabilization target for the adjudication

\footnotetext{
${ }^{23}$ The assumption of uniform recharge can be relaxed without changing the key insights from our theory.

${ }^{24}$ An additional assumption is needed to guarantee that a unique value of $h^{m a}$ solves $\dot{h}^{m a}=\alpha R+\theta\left(\bar{h}^{m r}-\right.$ $\left.h^{m a}\right)-\alpha N w^{a}\left(h^{m a}\right)=0$, as shown in panel (b): $\frac{d^{2} w^{a}(h)}{d h^{2}} \geq 0$, which holds if $\pi_{w w w} \pi_{w h}-\pi_{w h h} \pi_{w w} \geq 0$.
} 
area $\bar{h}^{m r}$, there is a unique steady-state water table $\bar{h}^{m a}$ and pumping rate $\bar{w}^{m a}=w^{a}\left(\bar{h}^{m a}\right)$ in the open access area. We denote this mapping $q: \bar{h}^{m r} \rightarrow \bar{h}^{m a}$.

The steady state for the adjudication area is found by substituting $\bar{h}^{m r}$ in equation (9) into equation (6) and setting $\dot{h}^{m r}=0$, yielding:

$$
R-\alpha N w^{a}\left(\bar{h}^{m a}\right)-(1-\alpha) N \bar{w}^{m r}=0
$$

Substituting $\bar{h}^{m a}=q\left(\bar{h}^{m r}\right)$ and rearranging equation (10), we obtain:

$$
\bar{w}^{m r}\left(\bar{h}^{m r}\right)=\frac{R-\alpha N w^{a}\left(q\left(\bar{h}^{m r}\right)\right)}{(1-\alpha) N}
$$

For a given stabilization target $\bar{h}^{m r}$, equation (11) gives the steady-state pumping limit $\bar{w}^{m r}=\bar{w}^{m r}\left(\bar{h}^{m r}\right)$ that needs to be imposed on landowners within the adjudication area. The steady states are depicted in panel (b) of Figure $3 .^{25}$ In summary, under the incomplete property rights regime, we have $h_{0} \geq h^{m a}(t), w^{a}\left(h_{0}\right) \geq w^{a}\left(h^{m a}(t)\right)$, and $w^{m r}(0) \geq w^{m r}(t)$ for $t \geq 0$.

Water trading and land prices. Tradeable property rights allow right holders to exchange water with other agricultural landowners or with municipalities. If there are heterogeneous endowments, incentives for trading are created. ${ }^{26}$ In particular, at the initial endowments, differences among landowners in the shadow values of water $\lambda^{m r}$ imply gains from trade. If $p^{w}$ is the unit price of water supported by a competitive water market, then landowners for whom $\lambda^{m r}<p^{w}\left(\lambda^{m r} \geq p^{w}\right)$ will be sellers (buyers) of water. When gains from trade are exhausted, $\lambda^{m r}=p^{w}$ for all landowners and all landowners use the same amount of water $w^{m r}$. Thus, a landowner with a given endowment $w^{e}$ makes net purchases from other agricultural landowners and municipalities equal to $w^{m r}-w^{e} .^{27}$

Under incomplete property rights, the land price for a given owner in the adjudication area is:

$$
V^{m r}=\int_{0}^{\infty}\left[\pi\left(w^{m r}(s), \bar{h}^{m r}\right)-p^{w}(s)\left(w^{m r}(s)-w^{e}(s)\right)\right] e^{-\delta s} d s
$$

Equation (12) captures temporary annual leases as well as transfers of perpetual groundwater rights. If a landowner sells her perpetual water rights to a municipality at a future time $t$, $w^{m r}(s)=0$ for $s \geq t$ and the proceeds from the sale, $\int_{t}^{\infty} p^{w}(s) w^{e}(s) e^{-\delta(s-t)} d s$, are capitalized

\footnotetext{
${ }^{25}$ It can be shown that $\bar{w}^{m a} \geq \bar{w}^{a} \geq \bar{w}^{m} r$ and $\bar{h}^{m r} \geq \bar{h}^{m a} \geq \bar{h}^{a}$.

${ }^{26}$ In practice, other sources of heterogeneity, such as differences in production technologies or depths to groundwater, can also generate trading if endowments are homogeneous.

${ }^{27}$ Landowners under the Mojave adjudication are allowed to buy and sell pumping rights (i.e., "paper trades") but not physical amounts of water. Assuming no banking or borrowing, which approximates the Mojave institution, the amount of water bought or sold by a landowner in each period, $w^{m r}-w^{e}$, must equal the amount applied to their parcel $w^{m r}$ net of their endowment $w^{e}$.
} 
into the current land price. The land price for landowners in the open access area is:

$$
V^{m a}=\int_{0}^{\infty} \pi\left(w^{m a}(s), h^{m a}(s)\right) e^{-\delta s} d s
$$

We made the simplifying assumption, above, that there are single water table heights in the two areas. In reality, there is a declining gradient in the water table as one moves from the adjudication to the open access area. At the boundary of the two areas, the water table height is the same for parcels under the adjudication and open access areas. That is, denoting water table height at the boundary as $h^{b}(t), \bar{h}^{m r} \geq h^{b}(t) \geq h^{m a}(t)$ for $t \geq 0$. This property has important implications for our RD estimator, as discussed below.

\subsection{Comparing across regimes}

We now compare land values between the full open access and incomplete property rights regimes to facilitate interpretation of an RD estimate in Section 4.

Proposition 1 If (i) $\bar{h}^{m r} \geq h^{a}(t)$, (ii) $\bar{h}^{m r} \geq h^{m a}(t)$, (iii) $h^{m a}(t) \geq h^{a}(t)$, and (iv) $w^{a}\left(h_{0}\right) \geq$ $w^{m a}(t) \geq w^{a}(t) \geq w^{m r}(t)$ for $t \geq 0$, then

(a) $V^{m r}-V^{a} \gtreqless 0$ (treatment effect has ambiguous sign)

(b) $V^{m r}-V^{m a} \gtreqless 0$ (estimated effect has ambiguous sign)

(c) $\left(V^{m r}\left(h^{b}\right)-V^{a}\right)-\left(V^{m r}\left(h^{b}\right)-V^{m a}\left(h^{b}\right)\right) \geq 0$ (estimated effect at the boundary is a lower bound for treatment effect at the boundary)

(d) $\left(V^{m r}-V^{a}\right)-\left(V^{m r}\left(h^{b}\right)-V^{a}\right) \geq 0$ (treatment effect at the boundary is a lower bound for treatment effect in the interior)

(e) $\frac{d}{d t}\left(V^{m r}\left(h^{b}\right)-V^{m a}\left(h^{b}\right)\right) \gtreqless 0$ (the change over time in the estimated effect at the boundary has ambiguous sign)

Proof. We establish conditions (i)-(iv) here and prove Proposition 1(a) -1(e) in Appendix A.1-A.5. It was shown in Sections 3.2 and 3.3 that $h_{0} \geq h^{a}(t)$ and $h_{0} \geq h^{m a}(t)$ for $t \geq 0$, respectively. Conditions (i) and (ii) follow from the definition $\bar{h}^{m r}=h_{0}$. To prove condition (iii), we show that $\dot{h}^{a} \leq \dot{h}^{m a}$ at any $h_{0} \geq h \geq \bar{h}^{a}$. Condition (iii) then follows from $h^{a}(0)=$ $h^{m a}(0)=h_{0}$. As shown in Section 3.2, $w^{a}\left(\bar{h}^{a}\right)=R / N$. For any $h \geq \bar{h}^{a}, w^{a}(h) \geq R / N$ by $\frac{d w^{a}}{d h}>0$. Using equations 2 and 5 , we write:

$$
\dot{h}^{m a}-\dot{h}^{a}=\theta\left(\bar{h}^{m r}-h\right)+(1-\alpha)\left(N w^{a}(h)-R\right)
$$


This difference is positive from $\bar{h}^{m r}=h_{0}$ and $w^{a}(h) \geq R / N$, which establishes condition (iii).

It follows immediately from conditions (i)-(iii) and $\frac{d w^{a}}{d h}>0$ that $w^{a}\left(h_{0}\right) \geq w^{m a}(t) \geq w^{a}(t)$ for $t \geq 0$. It remains to show that $w^{a}(t) \geq w^{m r}(t)$ for $t \geq 0$. In Section 3.3, we showed that $w^{m r}(0)=R / N$ and $\dot{w}^{m r} \leq 0$, which implies $w^{m r}(t) \leq R / N$ for $t \geq 0$. We showed earlier that $w^{a}(t) \geq R / N$ for $t \geq 0$ and so condition (iv) is established.

\section{Empirical strategy}

This section draws on the theoretical results from Section 3 to inform our empirical strategy. We first introduce our estimand of interest. We then propose a spatial RD estimator that exploits the spatially-incomplete nature of groundwater rights over the Mojave aquifer. Theoretical predictions from Section 3 inform the relationship between the spatial RD estimate and the estimand, what drives the RD estimate, and whether the RD estimate varies over time.

\subsection{Causal estimand}

We are interested in whether the Mojave adjudication regime led to net benefits for landowners relative to a full open access counterfactual. For the population of parcels under adjudication, this is the difference in potential outcomes $V^{m r}$ (see equation (12)) and $V^{a}$ (see equation (3)). Our estimand of interest is the population average treatment effect:

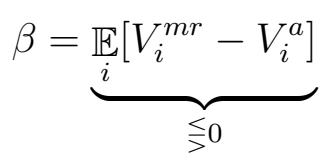

$\beta$ is the average net benefit of adjudication relative to the full open access counterfactual. By Proposition 1(a), $\beta$ is of unknown sign. The reason is that relative to a full open access regime, parcels under adjudication benefit from a higher water table and the ability to trade groundwater rights, but also bear the cost of restricted pumping. Unfortunately, $\beta$ cannot be directly estimated since $V_{i}^{m r}$ and $V_{i}^{a}$ are potential outcomes under counterfactual states and thus are not simultaneously observed (Holland, 1986).

\subsection{Spatial regression discontinuity estimator}

Instead, we consider a spatial RD estimator that exploits the boundary of the Mojave adjudication regime. Define $d_{i}$ as parcel $i$ 's distance to the adjudication boundary. $d_{i}$ is normalized 
so that a parcel is under adjudication when $d_{i} \geq 0$ (i.e., blue area inside the red and purplelined box in Figure 2) and under open access when $d_{i}<0$ (i.e., blue area outside the red and purple-lined box in Figure 2). Our spatial RD estimator is:

$$
\begin{aligned}
\hat{\beta}^{R D} & =\underset{d_{i \downarrow} \downarrow 0}{\mathbb{E}}\left[V_{i}^{m r}\right]-\underset{d_{i} \uparrow 0}{\mathbb{E}}\left[V_{i}^{m a}\right] \\
& =\underbrace{\underset{i: d_{i}=0}{\mathbb{E}}\left[V_{i}^{m r}-V_{i}^{m a}\right]}_{\lesseqgtr 0}
\end{aligned}
$$

where the first equality defines our spatial RD estimator at the adjudication boundary. The second equality uses the RD identifying assumption that expected land price under open access is continuous at the boundary, $d_{i}=0 .{ }^{28}$ In particular, it implies that the water table height $h_{i}\left(d_{i}\right)$ and other unobserved characteristics are continuous at $d_{i}=0$. While $\hat{\beta}^{R D}$ removes the effect of the water table, the remaining opposing influences of gains from groundwater rights trading and losses from pumping restrictions imply that $\hat{\beta}^{R D}$ remains of unknown sign, as indicated by Proposition 1(b).

How does $\hat{\beta}^{R D}$ relate to $\beta$ ? There are both internal and external validity considerations. Turning first to internal validity, let us denote the local $\beta$ for parcels at the boundary as $\beta_{i: d_{i}=0}$. The difference between $\beta_{i: d_{i}=0}$ and $\hat{\beta}^{R D}$ is:

$$
\beta_{i: d_{i}=0}-\hat{\beta}^{R D}=\underbrace{\underset{i: d_{i}=0}{\mathbb{E}}\left[\left(V_{i}^{m r}-V_{i}^{a}\right)-\left(V_{i}^{m r}-V_{i}^{m a}\right)\right]}_{\geq 0}
$$

which is weakly positive by Proposition 1(c). The RD estimator serves as a weak lower bound for the treatment effect at the boundary because it omits the benefit of a higher water table. ${ }^{29}$ This lower bound argument can also be interpreted from the perspective of spillover effects. As our theory shows, in a spatially-incomplete groundwater rights regime, water from the adjudicated area spills into the open access area, raising land prices for remaining open access parcels. Because this spillover benefit to open access parcels under adjudication would not occur under a full open access regime, the RD estimator produces a lower value than our estimand. ${ }^{30}$

\footnotetext{
${ }^{28}$ Specifically, following Hahn, Todd and Van der Klaauw (2001), the identifying assumption states that $\mathbb{E}\left[V_{i}^{m a}\right]$ is continuous in $d_{i}$ at $d_{i}=0$.

${ }^{29}$ Furthermore, it can be shown that an estimand defined as the average difference in land value between a spatially incomplete groundwater rights and open access regimes will be lower than that for a spatially complete groundwater rights regime. This is because there are no groundwater spillovers to open access areas when rights are complete. Thus our RD estimate is also a weak lower bound on the net benefit of a spatially complete groundwater rights regime.

${ }^{30}$ Using the same argument, Section 7.2 shows RD evidence of groundwater well drilling in open access
} 
The external validity of our RD estimate depends on the spatial structure of other land parcel characteristics. Water levels increase as one moves into the adjudication area away from the boundary. If other land parcel characteristics are uncorrelated with distance to the boundary, then by Proposition $1(\mathrm{~d})$, the treatment effect at the boundary serves as a further lower bound for the treatment effect in the interior of the adjudication area. Thus, this orthogonality assumption, together with Propositions 1(c) and 1(d) jointly imply that the spatial RD estimate is a lower bound for the population average net benefit: $\hat{\beta}^{R D}<\beta$.

Our theory also informs the various components of our spatial RD estimate. Specifically, using equations (12) and (13) and further allowing heterogeneity in water use $\left(w_{i}^{m r}\right)$ and endowments $\left(w_{i}^{e}\right)$ for adjudicated parcels, and in water use $\left(w_{i}^{m a}\right)$ for open access parcels, we can explicitly decompose $\hat{\beta}^{R D}$ into the following components (see Appendix A.6 for details):

$$
\begin{aligned}
\hat{\beta}^{R D} & =\underbrace{\underset{i: d_{i}=0}{\mathbb{E}}\left[\int_{0}^{\infty}\left[\pi\left(w_{i}^{e}(s), h_{i}(s)\right)-\pi\left(w_{i}^{m a}(s), h_{i}(s)\right)\right] e^{-\delta s} d s\right]}_{\leq 0 \text { restriction cost }} \\
& +\underbrace{\underset{i: d_{i}=0}{\mathbb{E}}\left[\int_{0}^{\infty}\left[\pi\left(w_{i}^{m r}(s), h_{i}(s)\right)-\pi\left(w_{i}^{e}(s), h_{i}(s)\right)-p^{w}(s)\left(w_{i}^{m r}(s)-w_{i}^{e}(s)\right)\right] e^{-\delta s} d s\right]}_{\geq 0 \text { gains from trade }}
\end{aligned}
$$

$\hat{\beta}^{R D}$ is positive when the gains from groundwater rights trading offset the cost of restricted pumping. ${ }^{31}$ In particular, for our RD sample of agricultural parcels, gains from trade would increase in parts of the aquifer with, among other features, expanding urban areas, whose demand for water drives up groundwater rights prices, allowing agricultural parcels to be net sellers of rights.

Finally, Section 3 defines land prices at the start of the program, when $t=0$ or in 1997. In this case, $\hat{\beta}^{R D}$ indicates whether landowners received a positive stream of discounted net benefits when the adjudication system was finalized. One may also be interested in whether continuation of the regime since 1997 has been economically justified. Our theory is agnostic on this matter: Proposition 1(e) shows that the time derivative of the estimated effect at the boundary is of ambiguous sign. To test this, we examine RD effects for different periods after adjudication was introduced.

areas near the boundary following the introduction of adjudication, consistent with increased groundwater under adjudication that spills over into open access areas.

${ }^{31}$ For simplicity, our theory in Section 3 ignores the small annual fee paid by landowners to administer the adjudication regime, set at around $\$ 5$ per acre-foot. Such fees provide another reason for why $\hat{\beta}^{R D}$ serves as a lower bound. 


\section{Data}

Based on Section 3, the ideal outcome variable is parcel price, which bundles together the present discounted value of a parcel's land and water assets. Two proxy measures for parcel price are available in San Bernardino County: sales value and assessed value. Unfortunately, sales records in San Bernardino are not required to include the value of adjudicated groundwater rights when such rights are jointly transferred with a land parcel. This limitation rules out the direct use of sales data for our analysis.

By contrast, land value assessments in San Bernardino are required by law to include the value of adjudicated water rights attached to a land parcel. Specifically, when evaluating a parcel, the assessor is required to contact the Mojave Water Agency, which keeps a record of who owns groundwater rights, transfers, and the value of transfers, to determine a value that is inclusive of groundwater rights held by that parcel. ${ }^{32}$

For our primary dataset, we use a single cross-section of 2015 data containing parcel-level assessed land value, size, location, and the last year of sale, obtained from the San Bernardino County Assessor. We impose several sample restrictions on this dataset. First, we restrict attention to parcels that were last sold since 1997, after adjudication was confirmed by the county court and thus applied to all parcels within the boundary. Next, our RD design is only applicable to land parcels with access to underlying local groundwater. Thus, we exclude parcels that do not overlie the aquifer. We further exclude parcels in urban areas, as defined by the Federal Highway Administration, because their water comes from municipal water systems, not local groundwater pumping. We further webscraped a panel of annual assessed land values from 1976 to 2014 (but missing 1977) from an online data portal maintained by San Bernardino County. These data, however, do not include parcel covariates (such as size and year of last sale) and are thus used only in examining how RD effects evolve over time.

We further collect several auxiliary datasets. The USGS digital elevation map provides parcel-level average slope and aspect (compass direction). ${ }^{33}$ Well completion reports from the California Department of Water Resources provides the location, drilling year, and other characteristics of private groundwater wells. We use these data to construct a parcel-level measure of proximity to a private groundwater well as well as to examine the timing of well drilling near the adjudication boundary. ${ }^{34}$ We use groundwater level data from USGS monitoring wells to examine trend breaks in average Mojave groundwater levels. Lastly, we collect data on groundwater rights endowments, trading volumes and prices from the Mojave

\footnotetext{
${ }^{32}$ The assessor, however, does not separately report the value of water rights, only the combined value of a parcel's land and water assets.

${ }^{33}$ Available here: https ://viewer nationalmap.gov/basic/

${ }^{34}$ Available here: https://data.ca.gov/dataset/well-completion-reports.
} 
Water Agency for various supporting analyses. ${ }^{35}$

Table C.1 shows summary statistics for the variables in our primary dataset. It includes parcels near the adjudication boundary used in our RD estimation as well as more distant parcels.

\section{Results}

This section presents our main RD result, robustness checks, and heterogeneity analyses.

\subsection{Specification}

To estimate our RD coefficient, $\hat{\beta}^{R D}$, from Section 4.2, we follow Hahn, Todd and Van der Klaauw (2001) and model log land value for parcel $i$ using a local polynomial regression

$$
\ln V_{i}=\beta^{R D} R_{i}+f\left(d_{i}\right)+\theta^{\prime} \mathbb{X}_{i}+\epsilon_{i}
$$

where, as in Section $4.2, d_{i}$ is normalized distance to the adjudication boundary. $R_{i}=$ $\mathbf{1}\left\{d_{i} \geq 0\right\}$ is an indicator variable equaling 1 when parcel $i$ is in the adjudication area and 0 otherwise. $f\left(d_{i}\right)$ is a flexible local polynomial function that is fully interacted with $R_{i}$, allowing for different parameters on either side of the boundary. For example, under a linear specification $f\left(d_{i}\right)=\alpha_{1}+\alpha_{2} d_{i}+\alpha_{3} d_{i} R_{i}$. In some models, we include a vector of covariates, $\mathbb{X}_{i}$, detailed below. For our baseline specification, standard errors are clustered at the zip code level to allow for arbitrary forms of heteroscedasticity and spatial autocorrelation among land parcels within the same zip code.

$\beta^{R D}$ is our RD coefficient of interest. ${ }^{36}$ We report $\mathrm{RD}$ point estimates using a mean squared error (MSE) optimal bandwidth which addresses the bias-variance trade-off inherent in RD bandwidth selection. However, inference based on the MSE-optimal bandwidth is generally invalid. We follow a recent econometrics literature that recommends reporting $p$-values and confidence intervals using an alternative robust bias-correction procedure for bandwidth selection (Calonico, Cattaneo and Titiunik, 2014; Calonico et al., 2019). ${ }^{37}$ In our baseline model, observations are uniformly weighted within bandwidths of equal length on

\footnotetext{
${ }^{35}$ Available here: http://www.mojavewater.org/annual_report.html and http://www.mojavewater . org/water_transfer_reports.html

${ }^{36}$ Note that $\beta^{R D}$ from equation (18) is the RD effect in terms of $\log$ land values, whereas in equation (16) it is defined in terms of (untransformed) land values.

${ }^{37}$ The use of different RD bandwidths for point estimation and inference implies reported confidence intervals that are not centered at reported point estimates.
} 
both sides of the threshold. Robustness checks consider alternative bandwidths, error structures (including a zip code-level wild bootstrap procedure), and other estimation choices.

\subsection{Interpretation of RD coefficient under Proposition 13}

Interpretation of the RD coefficient in equation (18) requires a brief aside on how assessed land values are calculated in California. Since 1978, Proposition 13 has limited property tax increases across California by capping the annual appreciation rate of assessed land value at $2 \%$ following a parcel sale. Strong housing demand in southern California over recent decades means that this $2 \%$ limit has regularly constrained increases in assessed value. This implies that, in any given year, the assessed land value of a previously transacted parcel likely captures its market price at the time of last sale, with a $2 \%$ annual adjustment.

There are two consequences of Proposition 13 that are germane to our RD analysis. First, for parcels last sold in 2015, the 2015 assessed land value equals its market value. Second, under certain conditions, we can use our single cross-section of 2015 assessed land values including parcels last sold since 1997 to recover an average RD effect across pooled 1997-2015 values. To see this, denote 2015 assessed log land value for parcel $i$ as

$$
\ln V_{i, 2015}=\ln V_{i, 2015-\tau_{i}}+r_{i} \tau_{i}
$$

where $\ln V_{i, 2015-\tau_{i}}$ is parcel $i$ 's $\log$ value when it was sold $\tau_{i}$ years ago (i.e., in year $2015-\tau_{i}$ ). $r_{i}$ is the average annual land value growth rate between $2015-\tau_{i}$ and 2015. If Proposition 13 always binds (i.e., $r_{i}=0.02$ for all $i$ ), then provided that $\tau_{i}$ is continuous at the boundary, the outcome in equation (18) effectively becomes $\ln V_{i, 2015-\tau_{i}}$, such that our RD estimate is a pooled average across 1997-2015 land values. If Proposition 13 does not always bind, ${ }^{38}$ our $\mathrm{RD}$ estimate still has a time-averaged interpretation provided that the percentage change since last sale, $r_{i} \tau_{i}$, is continuous at the boundary.

These two implications of Proposition 13 address concerns about the potential noisiness of assessed land values. In years when a parcel is not transacted, assessors typically determine the value of that parcel's land and groundwater assets by using market information from comparable land and groundwater transactions. These calculations can be noisy. While we remain unable to observe market (or true) values in years when a parcel is not transacted, Proposition 13 allows us to back out a parcel's market value in the year of its last sale despite using only a single cross section of assessed land values.

\footnotetext{
${ }^{38}$ Using our panel dataset of land values, we calculate that Proposition 13 's $2 \%$ annual cap was binding for $91 \%$ of parcel-year observations in our sample.
} 


\subsection{Covariate smoothness}

To assess the validity of our RD estimator, we begin by examining whether relevant covariates exhibit discontinuities at the adjudication boundary. Our RD identifying assumption, introduced in Section 4.2, requires that land prices under open access be continuous at the adjudication boundary. In some places, however, the boundary is defined according to the surface water drainage area of the Mojave River. Because the boundaries of a drainage area typically corresponds to a local elevation peak, surface topological features may vary systematically across the boundary. For example, the slope of the land may change at the boundary. Likewise, the aspect of the land, or its compass direction and thus sunlight exposure, may also vary systematically at the boundary. ${ }^{39}$ Both slope and aspect can influence a parcel's land value. Our identifying assumption also implies that groundwater levels be continuous at the boundary, which data limitations unfortunately prevent us from directly testing. Instead, we examine whether the presence of a privately-drilled groundwater well within one mile of a parcel, which we view as an imperfect proxy for groundwater availability and possibly irrigation, jumps at the boundary. ${ }^{40}$

We also examine covariates that inform the interpretation of our RD coefficient. As discussed in Section 6.2, our estimate would capture an average RD effect across 19972015 land values if there were no boundary jump in the year of last sale (in the case when Proposition 13 always binds), or in the percentage change in land value since last sale (in the case when Proposition 13 does not always bind). Finally, to ensure that our RD effect is not capturing differences in land value due to different parcel sizes, we also examine whether there is a discontinuity in land parcel size across the boundary.

Table 1 shows $\hat{\beta}^{R D}$ for each covariate, displayed across columns. Specifically, we estimate separate versions of equation (18), where each covariate in $\mathbb{X}_{i}$ serves as the dependent variable. Each model uses a local linear function for $f\left(d_{i}\right)$ and excludes other covariates as

\footnotetext{
${ }^{39}$ We thank Jeff Vincent for this insight.

${ }^{40}$ Monitoring wells, which are specifically designed to measure groundwater levels, are spatially sparse in this part of California. For example, the calculation for average groundwater level in 2015 shown in Figure 1 was based on only nine monitoring wells. Spatial interpolations with such a small number of point measurements would generate imputed maps of groundwater levels that likely spatially vary more smoothly than the actual groundwater table, and thus would be uninformative of groundwater levels at the boundary. Alternatively, California's Department of Water Resources well completion reports document privately-drilled wells, which are far more spatially dense than monitoring wells. However, depth to well water for privately-drilled wells varies with well characteristics and may not correspond to the true groundwater level. Furthermore, depth to well water is only recorded at the moment of initial drilling and not during the period when we observe land values. While we cannot use the well completion reports to measure groundwater levels, we use these data to determine whether a parcel is within one mile of a privately drilled well, which serves as a proxy measure for groundwater availability and possibly the presence of irrigation. We note, however, that the use of distance to construct this measure will necessarily impose some spatial continuity.
} 
Table 1: Examining covariate smoothness

\begin{tabular}{|c|c|c|c|c|c|c|}
\hline & $\begin{array}{c}(1) \\
\text { Slope }\end{array}$ & $\begin{array}{c}(2) \\
\text { Aspect }\end{array}$ & $\begin{array}{c}\text { (3) } \\
\text { Near well? }\end{array}$ & $\begin{array}{c}(4) \\
\text { Last sales } \\
\text { year }\end{array}$ & $\begin{array}{c}(5) \\
\text { Pct. change since } \\
\text { last sale }\end{array}$ & $\begin{array}{l}(6) \\
\text { Size }\end{array}$ \\
\hline$\hat{\beta}^{R D}$ & $\begin{array}{c}3.027 \\
(0.188) \\
{[-.833,4.23]}\end{array}$ & $\begin{array}{c}-21.510 \\
(0.929) \\
{[-53.249,48.632]}\end{array}$ & $\begin{array}{c}0.007 \\
(0.721) \\
{[-.234, .162]}\end{array}$ & $\begin{array}{c}-1.034 \\
(0.184) \\
{[-2.91, .559]}\end{array}$ & $\begin{array}{c}25.587 \\
(0.635) \\
{[-118.806,194.822]}\end{array}$ & $\begin{array}{c}3.383 \\
(0.181) \\
{[-4.675,24.823]}\end{array}$ \\
\hline $\begin{array}{l}\text { Avg. OA value } \\
\text { Observations } \\
\text { Zip codes }\end{array}$ & $\begin{array}{c}1.858 \\
3060 \\
27\end{array}$ & $\begin{array}{c}150.759 \\
3060 \\
27\end{array}$ & $\begin{array}{c}0.827 \\
3060 \\
27\end{array}$ & $\begin{array}{c}1992.363 \\
3060 \\
27\end{array}$ & $\begin{array}{l}274.929 \\
3047 \\
27\end{array}$ & $\begin{array}{c}11.818 \\
3060 \\
27\end{array}$ \\
\hline
\end{tabular}

NotES: Estimates of $\beta^{R D}$ from equation (18) with each covariate as outcome. Specification includes a local linear model for $f\left(d_{i}\right)$ and excludes $\mathbb{X}_{i}$. Covariates indicated across columns rows. Column 1 is average slope measured in degrees relative to level surface. Column 2 is average aspect measured in compass direction between 0 and 360. Column 3 examines a dummy variable equaling one if a parcel is within 1 mile of a well. Column 4 examines the most recent year in which the parcel was sold. Column 5 examines a parcel's percentage change in value since its last sale. Column 6 examines parcel size in acres. Average covariate value for sample open access parcels shown. Bandwidths taken from baseline log land value model in column 1 of Table 2. Observations are uniformly weighted. Standard errors clustered at the zip code level. $p$-values in parentheses. $95 \%$ confidence intervals in brackets.

regressors. We do not detect statistically precise $\mathrm{RD}$ effects across these six covariates. In particular, absence of a discontinuity in the last year of sale and in the percentage change in land value since that year shown in columns 4 and 5 imply that our RD estimate on 2015 assessed land value reflects the average RD effect across the 1997-2015 period.

Figure B.2 plots binned average covariate values as a function of distance to the boundary to visualize the magnitudes of the $\mathrm{RD}$ effects in Table 1 relative to covariate means in the open access area near the boundary. The only covariate whose noisy RD effect may have a meaningful magnitude is parcel slope. A potential discontinuity in slope is consistent with the surface water drainage basin defining a portion of the boundary as land slopes need not be equal at the dividing line between two basins. However, the sign and magnitude of this jump in parcel slope should mitigate identification concerns. Prior hedonic studies find measures of greater slope tend to lower agricultural land values, possibly through increased risk of soil erosion (Palmquist and Danielson, 1989; Schlenker, Hanemann and Fisher, 2005) but that the effect, when measured in degrees, tends to be small (Bigelow et al., 2017). ${ }^{41}$ Thus, an RD effect on slope of 3 degrees implies an $\mathrm{RD}$ estimate on land values that is downward biased, but that the magnitude of the bias is likely small. In a robustness check, we include slope and other covariates as controls when estimating the RD effect on land values.

\footnotetext{
${ }^{41}$ Bigelow et al. (2017) finds that a 1 degree increase in slope is correlated with a $1 \%$ decrease in agricultural land values. Applied to the RD effect on slope from column 1 of Table 1, this suggests a $3 \%$ decrease in agricultural land values, respectively. By contrast, our baseline RD effect on land values is $220 \%$.
} 


\subsection{Main RD estimate and robustness checks}

Figure 4: Graphical RD effect

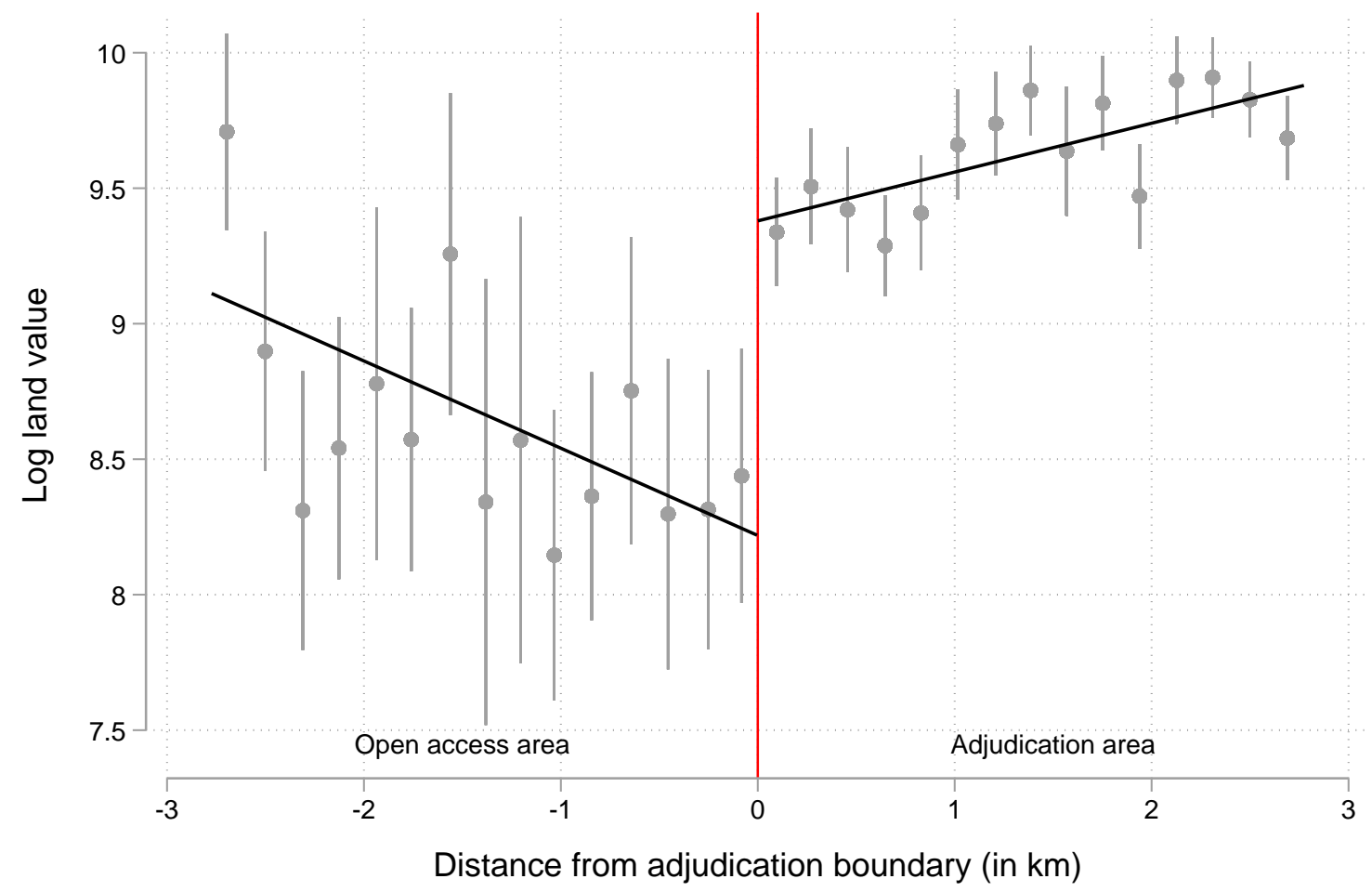

Notes: Vertical axes shows log land value. Horizontal axes shows normalized distance in kilometers, $d_{i}$, to adjudication boundary with $d_{i} \geq 0$ indicating the adjudication area and $d_{i}<0$ indicating the open access area. Mean and $95 \%$ confidence intervals shown for the outcome within equally-spaced distance bins. Solid lines show linear functions fitted over unbinned data, separately for each side of the boundary.

We first present our main RD result graphically. Figure 4 plots log land value, our main outcome of interest, against distance to the adjudication boundary, $d_{i}$. We show $\log$ land value as local average means across different binned distances as well as fitted local linear functions within the MSE-optimal bandwidth, estimated separately for each side of the boundary. There is a clear jump in land values at the discontinuity. ${ }^{42}$ We conduct a continuity test provided by Cattaneo, Jansson and Ma (2019), an alternative to the McCrary (2008) procedure that avoids prebinning data, and do not detect a discontinuity in the density of the distance variable at the threshold. ${ }^{43}$

\footnotetext{
${ }^{42}$ Additionally, we find that land values are generally increasing from left to right when examining a wider bandwidth, as shown in Figure B.3. While this spatial pattern is not identified using our RD design, this is consistent with our theoretical prediction that groundwater levels rise as one moves from the open access area into the interior of the adjudication area.

${ }^{43}$ We further note that traditional RD sorting concerns are lessened in our context. First, land parcels are fixed in space. Second, although there could be unobserved preference heterogeneity among landowners
} 
Table 2: Main RD results

\begin{tabular}{lcccc}
\hline & $(1)$ & $\begin{array}{c}(2) \\
\text { Outcome is log land value }\end{array}$ & $(4)$ \\
\hline$\hat{\beta}^{R D}$ & \multicolumn{5}{c}{} \\
& 1.161 & 1.344 & 1.216 & 1.345 \\
& $(0.019)$ & $(0.031)$ & $(0.008)$ & $(0.032)$ \\
& {$[.207,2.32]$} & {$[.123,2.644]$} & {$[.322,2.196]$} & {$[.125,2.724]$} \\
Percentage effect (\%) & 219 & 284 & 237 & 284 \\
& {$[23,918]$} & {$[13,1307]$} & {$[38,799]$} & {$[13,1423]$} \\
& & & & \\
Polynomial order & 1 & 2 & 1 & 1 \\
Covariates & No & No & Yes & No \\
Last sales year & $1997-2015$ & $1997-2015$ & $1997-2015$ & 2015 \\
Bandwidth & 2.774 & 4.715 & 3.126 & 3.073 \\
Observations & 3060 & 5341 & 3535 & 206 \\
Zip codes & 28 & 30 & 28 & 24 \\
\hline
\end{tabular}

NoTES: Estimates of $\beta^{R D}$ from equation (18) with $\log$ land value as outcome. Column 1 uses a local linear function for $f\left(d_{i}\right)$, excludes covariates, and includes all parcels that were last sold between 1997-2015. Column 2 uses a local quadratic function for $f\left(d_{i}\right)$. Column 3 includes a land parcel's average slope, average aspect, size, last sales year, and a dummy for whether the parcel is within one mile of a groundwater well as covariates. Column 4 restricts the sample to only parcels last sold in 2015. Point estimates use MSE-optimal bandwidth, with bandwidth reported. Inference based on robust bias-corrected standard errors, clustered at the zip code level, following Calonico, Cattaneo and Titiunik (2014) and Calonico et al. (2019). Common bandwidths employed on both sides of the threshold. Observations are uniformly weighted. Percentage effects are $100\left(e^{\hat{\beta}^{R D}}-1\right) . p$-values in parentheses. $95 \%$ confidence intervals in brackets.

We now turn to estimates of $\beta^{R D}$ from equation (18), shown in Table 2. For our baseline model, column 1 uses a local linear function for $f\left(d_{i}\right)$, excludes covariates, and includes all parcels last sold in the period 1997-2015. The statistically precise RD estimate of 1.161 translates to a $219 \%$ increase in land value. With mean land value for open access parcels within $1 \mathrm{~km}$ of the boundary at $\$ 12,100$, this implies a land value increase of $\$ 26,500$ (in 2015 dollars). To independently verify the magnitude of this effect, we compare this average land value increase to the average value of perpetual groundwater rights held by adjudicated parcels in our RD sample, which equation (17) indicates is an upper bound on our RD estimate (see Appendix A.7 for details). In 2015, this value was $\$ 195,000$.

The rest of Table 2 offers several robustness checks. Column 2 models $f\left(d_{i}\right)$ using a local

(e.g., some landowners may strongly prefer parcels with secure rights to water), competition in the land market implies that the value of an individual parcel's attributes is determined by the aggregate distribution of preferences across the market and not by individual preferences of that parcel's buyer and seller (Rosen, 1974). 
quadratic model. To address remaining concerns about potentially large, though imprecise, jumps in the covariates examined in Table 1, column 3 augments our baseline specification by including these covariates. ${ }^{44}$ Lastly, to examine parcels whose assessed value equals the sales value, column 4 restricts our sample to parcels transacted in 2015. All three robustness checks detect positive and statistically significant RD effects that are similar in magnitude to our baseline result in column 1.

Table 3: Robustness: alternative bandwidths

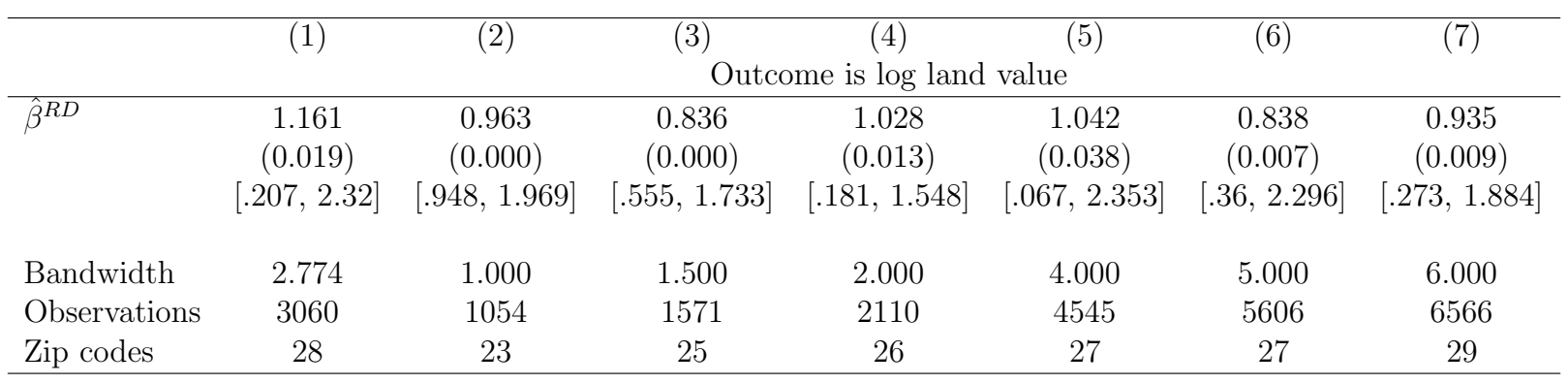

Notes: Estimates of $\beta^{R D}$ from equation (18) with log land value as outcome. All models use a local linear model for $f\left(d_{i}\right)$, exclude covariates, and uniformly weights observations. Column 1 replicates baseline model in column 1 of Table 2. Column 2-7 use narrower and wider bandwidths, imposing the same bandwidth for point estimates and zip code-clustered standard errors. Common bandwidths employed on both sides of the threshold. Observations are uniformly weighted. $p$-values in parentheses. $95 \%$ confidence intervals in brackets.

We next consider several additional robustness checks to the baseline result in column 1 of Table 2. Table 3 presents RD estimates using bandwidths smaller than one-half and larger than twice that of the baseline MSE-optimal bandwidth, showing also the number of parcels at different bandwidths around the boundary. Our RD result is not sensitive to these different bandwidth sizes.

Table C.2 considers various error structures and variance estimation procedures. Our main RD sample uses zip code-clustered standard errors with 28 zip codes. To address potential issues with having few clusters (Cameron, Gelbach and Miller, 2008), column 2 conducts a zip code-level wild bootstrap procedure specific for RD designs following He and Bartalotti (2020). This has little influence on the precision of our RD estimate. We further show in columns 3-6 that our RD result is insensitive to whether variance estimation is undertaken using zip code-level clustering, nearest neighbor matching, or both. Column 7 shows that our RD result also holds when applying a local randomization method that allows for exact inference in finite samples, but requires the additional assumption that potential outcomes are non-random (Cattaneo, Frandsen and Titiunik, 2015; Cattaneo, Titiunik and

\footnotetext{
${ }^{44}$ Column 3 of Table 2 includes all covariates shown in Table 1 except for the percentage change in land value since last sale because that variable is constructed using assessed 2015 land value, our outcome of interest in Table 2.
} 
Vazquez-Bare, 2016).

In Table C.3, we estimate the RD coefficient allowing the MSE-optimal bandwidth to differ on both sides of the discontinuity and consider bandwidths that are coverage errorrate (CER) optimal (Calonico, Cattaneo and Farrell, 2019). We also alternatively weight observations using a triangular, rather than a uniform, kernel. Our results are stable across these bandwidth selection choices.

Table 4: Placebo boundary tests

\begin{tabular}{|c|c|c|c|c|c|c|}
\hline & (1) & $(2)$ & $(3)$ & $(4)$ & $(5)$ & $(6)$ \\
\hline & \multicolumn{6}{|c|}{ Outcome is log land value } \\
\hline$\hat{\beta}^{R D}$ & $\begin{array}{c}0.014 \\
(0.640) \\
{[-1.098, .675]}\end{array}$ & $\begin{array}{c}-0.092 \\
(0.867) \\
{[-1.177, .992]}\end{array}$ & $\begin{array}{c}0.028 \\
(0.995) \\
{[-1.655,1.645]}\end{array}$ & $\begin{array}{c}-0.191 \\
(0.493) \\
{[-.892, .43]}\end{array}$ & $\begin{array}{c}0.052 \\
(0.755) \\
{[-.379, .522]}\end{array}$ & $\begin{array}{c}-0.036 \\
(0.739) \\
{[-.697, .494]}\end{array}$ \\
\hline Dist. to true boundary $(\mathrm{km})$ & -9 & -6 & -3 & 3 & 6 & 9 \\
\hline Bandwidth & 2.274 & 2.410 & 6.185 & 3.748 & 3.213 & 3.495 \\
\hline Observations & 218 & 449 & 4183 & 6585 & 6311 & 6523 \\
\hline Zip codes & 10 & 22 & 23 & 33 & 31 & 32 \\
\hline
\end{tabular}

Notes: Estimates of $\beta^{R D}$ from equation (18) with log land value as outcome. All models use a local linear model for $f\left(d_{i}\right)$ and exclude covariates. Columns use placebo boundaries set 9,6 , and 3 kilometers within the open access (i.e., $d_{i}<0$ ) and adjudication areas (i.e., $d_{i} \geq 0$ ). Point estimates use MSE-optimal bandwidth, with bandwidth reported. Inference based on robust bias-corrected standard errors, clustered at the zip code level, following Calonico, Cattaneo and Titiunik (2014). Common bandwidths employed on both sides of the threshold. Observations are uniformly weighted. $p$-values in parentheses. $95 \%$ confidence intervals in brackets.

Finally, Table 4 conducts placebo tests by estimating RD effects using alternative locations for the boundary. Because there is no actual spatial discontinuity between adjudication and open access regimes across these placebo boundaries, we should not detect any RD effects. For models in columns 1-3, we create false boundaries that are 9, 6, and 3 kilometers, respectively, within the open access area relative to the real boundary. In columns 4-6, we create similarly spaced false boundaries within the adjudication area. We do not detect RD effects using any of these false boundaries.

\subsection{Heterogeneity}

We now turn to heterogeneity analyses, across time and space. Our main RD estimate using 2015 assessed land values pools parcels that were last sold within the 1997-2015 period. The presence of Proposition 13, together with columns 5 and 6 of Table 1 showing no boundary discontinuity in the last year of sale or the percentage change in land value since last sale, suggest that our main RD estimate reflects the average RD effect over the 1997-2015 period, rather than the effect for only 2015. A natural question, then, is whether this effect has 
changed since the program was introduced, which Proposition 1(e) indicates is ambiguously signed. Another related question is: what is the magnitude of the RD effect before 1997 ?

Table 5: Heterogeneity across time

\begin{tabular}{|c|c|c|c|c|c|}
\hline & (1) & $(2)$ & (3) & (4) & (5) \\
\hline & & Outcome is & og land value & & \\
\hline$\hat{\beta}^{R D}$ & $\begin{array}{c}0.427 \\
(0.253) \\
{[-.25, .949]}\end{array}$ & $\begin{array}{c}0.696 \\
(0.155) \\
{[-.22,1.379]}\end{array}$ & $\begin{array}{c}1.728 \\
(0.045) \\
{[.042,3.797]}\end{array}$ & $\begin{array}{c}1.176 \\
(0.041) \\
{[.049,2.225]}\end{array}$ & $\begin{array}{c}1.159 \\
(0.065) \\
{[-.069,2.296]}\end{array}$ \\
\hline Sample period & 1976-1979 & 1980-1989 & 1990-1996 & 1997-2005 & 2006-2014 \\
\hline Bandwidth & 1.157 & 1.525 & 2.170 & 1.689 & 2.141 \\
\hline Observations & 1065 & 1887 & 715 & 662 & 932 \\
\hline Zip codes & 21 & 22 & 21 & 21 & 21 \\
\hline
\end{tabular}

Notes: Estimates of $\beta^{R D}$ from equation (18) with log land value as outcome from a panel of assessed land values between 1976-2014 (missing 1977). Each model estimated over different indicated time intervals. All models use a local linear model for $f\left(d_{i}\right)$ and exclude covariates. Point estimates use MSE-optimal bandwidth, with bandwidth reported. Inference based on robust bias-corrected standard errors, clustered at the zip code level, following Calonico, Cattaneo and Titiunik (2014). Common bandwidths employed on both sides of the threshold. Observations are uniformly weighted. $p$-values in parentheses. $95 \%$ confidence intervals in brackets.

To shed light on these questions, we turn to our panel of annual assessed land values covering the 1976-2014 period. Table 5 reports RD estimates from equation (18) estimated separately across various time periods. ${ }^{45}$ Three results from Table 5 are worth noting. First, the RD estimate has changed very little since the introduction of adjudication, as shown in columns 4 and $5{ }^{46}$ That our estimates remain positive across time suggests that the continuation of adjudication has been economically justified. Second, we detect a statistically precise RD effect in the early 1990s. Because a subset of users already faced adjudication starting in 1993, these effects reflect a combination of implemented and anticipated RD effects. Third, as columns 1 and 2 show, in the period before the adjudication process began, the RD effect was smaller than the post-adjudication RD effect and not statistically

\footnotetext{
${ }^{45}$ We are interested in the time-evolution of land values since 1976. However, because of Proposition 13, land values of parcels not sold in a given assessment year are likely to capture values during the year of last sale and not values during the year of assessment. Including parcels sold prior to the assessment year would result in an artificially-smoothed RD estimate over time. Unlike our main dataset of 2015 land values obtained from the land assessor, we are unable to drop parcels from our webscraped panel dataset that were transacted earlier because this dataset does not explicitly contain information on year of last sale. To address this, the estimating samples in Table 5 attempt to detect parcels sold during the assessment year by including only parcels for which there is a change in owner name that year or for which the growth rate in assessed land value exceeded $2 \%$.

${ }^{46}$ Following footnote 45 , because we need to infer when parcels were sold in our panel dataset, the estimating sample (and thus RD estimates) in columns 4-5 of Table 5 differs slightly from our that of our main RD estimate in Table 2 using 2015 assessed land values for which we observe year of last sale.
} 
significant. In particular, the 1976-1979 RD effect was roughly 37\% of the post-1996 RD effect (see Figure B.4 for a graphical RD presentation on 1976-1979 land values).

There are two explanations for the smaller noisy RD effects prior to the 1990s. First, recall that there was an earlier failed attempt at adjudication during 1966-1976 and discussions over future adjudication continued through the 1970s and 1980s. Because those earlier proposals also foresaw management by the Mojave Water Agency, whose spatial boundaries are largely unchanged since 1960, any anticipation from an eventual adjudication could be capitalized in pre-1990 land values. A second explanation is that the pre-1990 RD effect captures a time-invariant jump in land values at the boundary that has nothing to do with the groundwater market. If so, this bias would show up in both pre-1990 and post-1990 RD estimates. In the presence of these two, possibly concurrent, explanations, one can look at the difference in RD estimates between columns 1 and 5 of Table 5, the two bookend periods of our panel dataset. This difference, which equals 0.73 but is not statistically precise, would remove any potential time-invariant bias. In the absence of any anticipated effects prior to 1990, this difference captures the true RD effect. In the presence of anticipated effects, this difference captures a lower bound on the true RD effect, where the bound is determined by the probability of eventual adjudication anticipated during the earlier period. ${ }^{47}$

Section 4.2 discusses how our spatial RD estimate depends on the market value of water. When this outside value is high, tradeable groundwater rights allow agricultural landowners to gain from selling rights to other users overlying the aquifer. For groundwater in the Mojave, this higher-value use is likely strongest in the more urban southern part of the region (see inset map in Figure 2).

To test whether urban water demand creates larger net benefits, Table 6 examines heterogeneity in the RD coefficient for the southern and northern subareas. Because rights trading can only occur within a particular subarea, one would expect the RD effect to be larger in the more urbanized southern subareas, all else equal. Column 1 replicates our baseline results. The model in column 2 restricts the sample to parcels in the southern subareas, while only northern subareas parcels are used to produce estimates in column 3. The RD coefficient for the southern subareas is almost five times larger than for the northern subareas, though statistical inference is complicated by the limited number of zip code clusters. As an alternative approach to modeling this heterogeneity, we interact $R_{i}$ and $f\left(d_{i}\right)$ from our

\footnotetext{
${ }^{47}$ To see this, denote $\hat{\beta}_{\text {pre }}^{R D}$ and $\hat{\beta}_{\text {post }}^{R D}$ as the RD estimates from columns 1 and 5 of Table 5 and $\beta^{R D}$ as the true RD effect of adjudication. Let $\gamma$ be time invariant bias in the estimates and $\vartheta \in[0,1]$ be the probability during the pre-adjudication period that adjudication would eventually be implemented, such that $\hat{\beta}_{\text {pre }}^{R D}=\vartheta \beta^{R D}+\gamma$ and $\hat{\beta}_{\text {post }}^{R D}=\beta^{R D}+\gamma$. If eventual adjudication was not anticipated in this earlier period (i.e., $\vartheta=0$ ), then $\hat{\beta}_{\text {post }}^{R D}-\hat{\beta}_{\text {pre }}^{R D}=\beta^{R D}$. If there was any anticipation (i.e., $\vartheta>0$ ), then $\hat{\beta}_{\text {post }}^{R D}-\hat{\beta}_{\text {pre }}^{R D}=\beta^{R D}(1-\vartheta)<\beta^{R D}$.
} 
Table 6: Heterogeneity across space

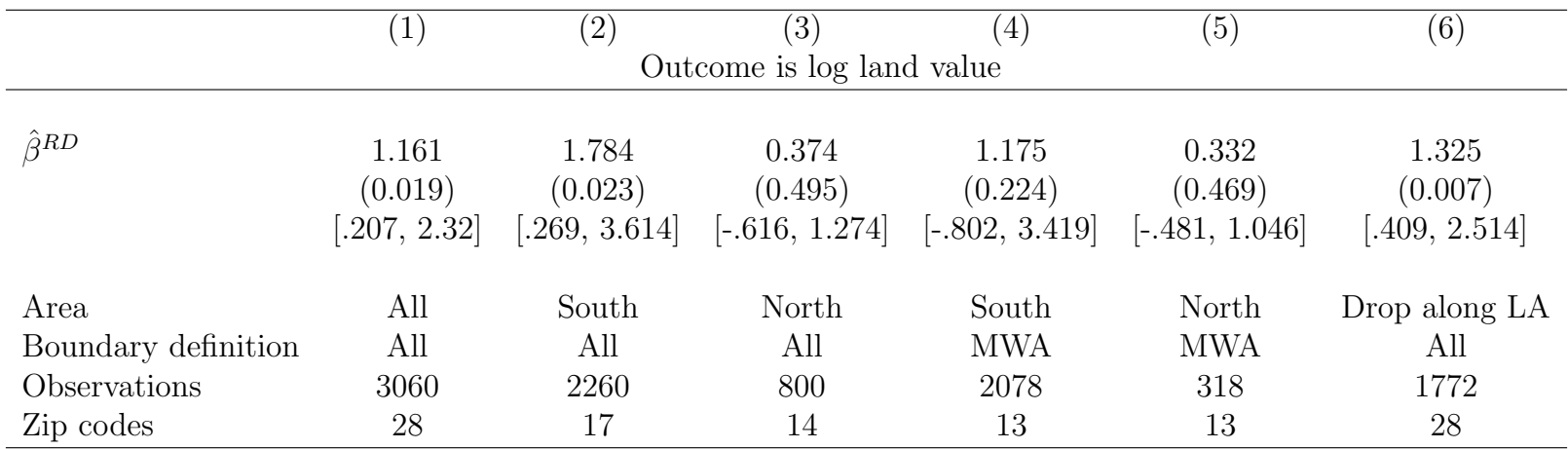

Notes: Estimates of $\beta^{R D}$ from equation (18) with log land value as outcome. All models use a local linear model for $f\left(d_{i}\right)$ and exclude covariates. Column 1 replicates baseline model in column 1 of Table 2. Columns 2 and 3 restrict the sample to land parcels in southern and northern subareas, respectively. Columns 4 and 5 further restrict the southern and northern subarea sample, respectively, by including only parcels whose nearest boundary is defined by the Mojave Water Agency (MWA). Bandwidths taken from baseline log land value model in column 1 of Table 2. Observations are uniformly weighted. Standard errors clustered at the zip code level. $p$-values in parentheses. $95 \%$ confidence intervals in brackets.

baseline model in equation (18) with a parcel's latitude. Figure B.5 plots how $\hat{\beta}^{R D}$ varies as one moves northward over the aquifer, showing a statistically significant decline. For parcels that are farthest north, the RD effect becomes negative, which is possible when the gain from trading rights is small. ${ }^{48}$

How much does the tradeability of groundwater rights contribute to the net benefit of the Mojave adjudication regime? Columns 1-3 of Table 6 merely show that gains from rights trading contribute to the net benefit, but not by how much. Note also that by controlling for groundwater level differences, our RD approach cannot definitively isolate the gains from groundwater trading. To conduct a back-of-the-envelope calculation, we assume that the benefit of a higher groundwater table can be identified using land value differences farther away from the boundary and that the gains from rights trading in the northern subareas is small. With these assumptions, we calculate that rights trading contributes to at most $39 \%$ of the net benefit of the Mojave adjudication regime, though this estimate is highly uncertain. ${ }^{49}$

\footnotetext{
${ }^{48}$ While the largest RD estimates occur in subareas with more municipalities, we also observe transaction of rights between agricultural users, as represented by our theory in Section 3. In particular, of all perpetual rights transactions in the period 1997-2015, $23 \%$ were between agricultural landowners and municipalities and $77 \%$ were between agricultural users. During that same period, of all transactions of annual leases to rights, $48 \%$ were between agricultural landowners and municipalities, $45 \%$ were between agricultural landowners, and $7 \%$ were between municipalities.

${ }^{49}$ To obtain $39 \%$, we divide the difference between RD estimates in columns 1 and 3 of Table 6 (i.e., 1.16-.37), which isolates the gains from rights trading, by the difference in average land values at the edge of the support shown in Figure B.3 (i.e., 9.85-7.81), which incorporates the water table gradient. This is an upper bound on the contribution of rights trading because gains from trading in the northern subareas, while smaller, are still positive (i.e., the true numerator is smaller) and because the true water table
} 
Table 6 also shows two final robustness checks. The RD effect may be heterogeneous depending on how the boundary is defined. The model in column 4 of Table 6 further restricts the sample of southern subarea parcels to those whose nearest boundary is defined by the spatial extent of the Mojave Water Agency (shown by red line segments in Figure 2) and not by the Mojave River drainage basin (shown by purple line segments in Figure 2). Column 5 uses a similar sample restriction for the northern subareas. Our RD effect does not differ greatly by how the boundary is defined. ${ }^{50}$ Finally, column 6 shows that our RD effect is robust to dropping parcels that are in the subarea directly adjacent to Los Angeles County. ${ }^{51}$

\section{Aggregate net benefit of adjudication}

We now turn to quantifying the aggregate net benefit of adjudication. We first use RD estimates from Section 6 to quantify the aggregate net benefit to agricultural parcels and then provide a back-of-the-envelope calculation for the aggregate net benefit to urban areas. Both values are potential lower bounds because they hold groundwater levels fixed. To explore whether adjudication led to more groundwater, we present three additional pieces of evidence implying that Mojave groundwater levels increased as a consequence of adjudication.

difference is likely larger (i.e., the true denominator is larger). Monte Carlo simulations using the robust bias-corrected inference statistics associated with columns 1 and 3 of Table 6 produces a 95\% confidence interval of $[-24 \%, 128 \%]$. This large uncertainty suggests that this back-of-the-envelope calculation should be interpreted with caution.

${ }^{50}$ Figure 2 shows that boundary segments defined by the Mojave Water Agency (shown by red line segments) are better represented in the southern parts of the adjudication area. Thus, an RD estimate using all parcels near the Mojave Water Agency boundary would have more southern subarea parcels and would not be comparable to an RD estimate using all parcels near the Mojave River drainage basin boundary. Table 6 addresses this by examining whether RD estimates differ by boundary definition separately for northern and southern subsamples. Alternatively, we also follow Gerardino, Litschig and Pomeranz (2017) by running an RD subsample test that weights all parcels by their latitude and do not find RD estimates that differ by boundary definition.

${ }^{51}$ Furthermore, within our RD sample there are no open access parcels that fall under the jurisdiction of a different water agency. This implies that for parcels near the Mojave Water Agency boundary, those that were adjudicated were under Mojave Water Agency jurisdiction while open access parcels were not part of any local water agency. Because the primary benefit of the Mojave Water Agency is groundwater access, we do not anticipate that this institutional difference results in discontinuities in non-adjudication Mojave Water Agency benefits at the boundary. However, because Mojave Water Agency parcels have to pay an annual fee of 16.75 cents per $\$ 100$ of assessed land value to the Mojave Water Agency for services aside from the adjudication, the presence of this fee may bias our RD estimate downwards. We believe the magnitude of this bias is small as this fee amounts to $\$ 23.95$ for the average adjudicated land parcel in our sample, which is negligible relative to our estimated coefficient. 


\subsection{Quantifying a (lower bound) aggregate net benefit}

We first quantify the aggregate net benefit of the Mojave adjudication regime for agricultural parcels. Proposition 1(c) states that our RD estimate is a lower bound on the local average treatment effect for agricultural parcels at the boundary. If one further assumes that other parcel characteristics are uncorrelated with distance to the boundary, Proposition 1(d) states that the local average treatment effect at the boundary is itself a lower bound for the population average treatment effect across all agricultural parcels. This orthogonality assumption, together with the south-north heterogeneity in the RD coefficient, enables a lower bound calculation for the aggregate net benefit of adjudication across agricultural parcels.

To that end, we multiply the heterogeneous RD effect separately for agricultural parcels in southern (i.e., column 2 of Table 6) and northern (i.e., column 3 of Table 6) subareas with each parcel's land value. We then sum this product across all adjudicated agricultural parcels. This results in a value of $\$ 350$ million (in 2015 dollars), or a $40 \%$ increase in total land value. ${ }^{52}$

Water access for urban areas is not tied to underlying groundwater but rather comes from municipal water systems. While this means we are unable to apply our spatial RD estimator to urban areas, Appendix A.8 details how an extension of our theory along with data on aggregate urban water allocation and trade combine to quantify the aggregate net benefit to urban areas. Our calculation is based on the following argument: unlike agricultural parcels, municipalities supplying water to urban areas held lower priority access to groundwater prior to adjudication and were likely pumping below their private optimum. If, following adjudication, one observed an increase in aggregate urban water consumption, the gain from increased water use must exceed the cost of purchasing groundwater rights from agricultural parcels, implying a positive aggregate urban net benefit. In Appendix A.8, we calculate for a range of demand elasticities found in the literature that adjudication resulted in an aggregate net benefit in the range of $\$ 72-131$ million (in 2015 dollars) for urban areas. Altogether, the aggregate net benefit to agricultural and urban areas of the groundwater market is $\$ 422-481$ million. By comparison, administrative and legal costs to set up the adjudication system during the 1990s was $\$ 40$ million (in 2015 dollars) (Figueroa, 2001). ${ }^{53}$

\footnotetext{
${ }^{52}$ Unlike the $219 \%$ average RD sample increase calculated in column 1 of Table 2, this aggregate percentage increase takes into account heterogeneity in RD estimates between northern and southern subareas and the number of parcels and their values in each region. Because there are many more parcels in the northern subareas where the RD effect is lower, the aggregate effect is weighted towards the northern RD effect.

${ }^{53}$ This value may understate total set-up costs if there were efforts to increase the likelihood of adjudication prior to the 1990s. Unfortunately, related cost figures are not available.
} 


\subsection{Did adjudication increase groundwater levels?}

The aggregate net benefit estimates in Section 7.1 omit any benefits of a higher groundwater table. If groundwater levels increased under the adjudication, these values are a strict lower bound on the net private and social benefits of the policy. If groundwater levels did not change, then the benefit of adjudication derives only from a more efficient allocation of that groundwater. We turn to three pieces of evidence beyond our main RD result to examine whether adjudication increased groundwater levels relative to the open access counterfactual.

Figure 5: Trend breaks in average Mojave groundwater levels

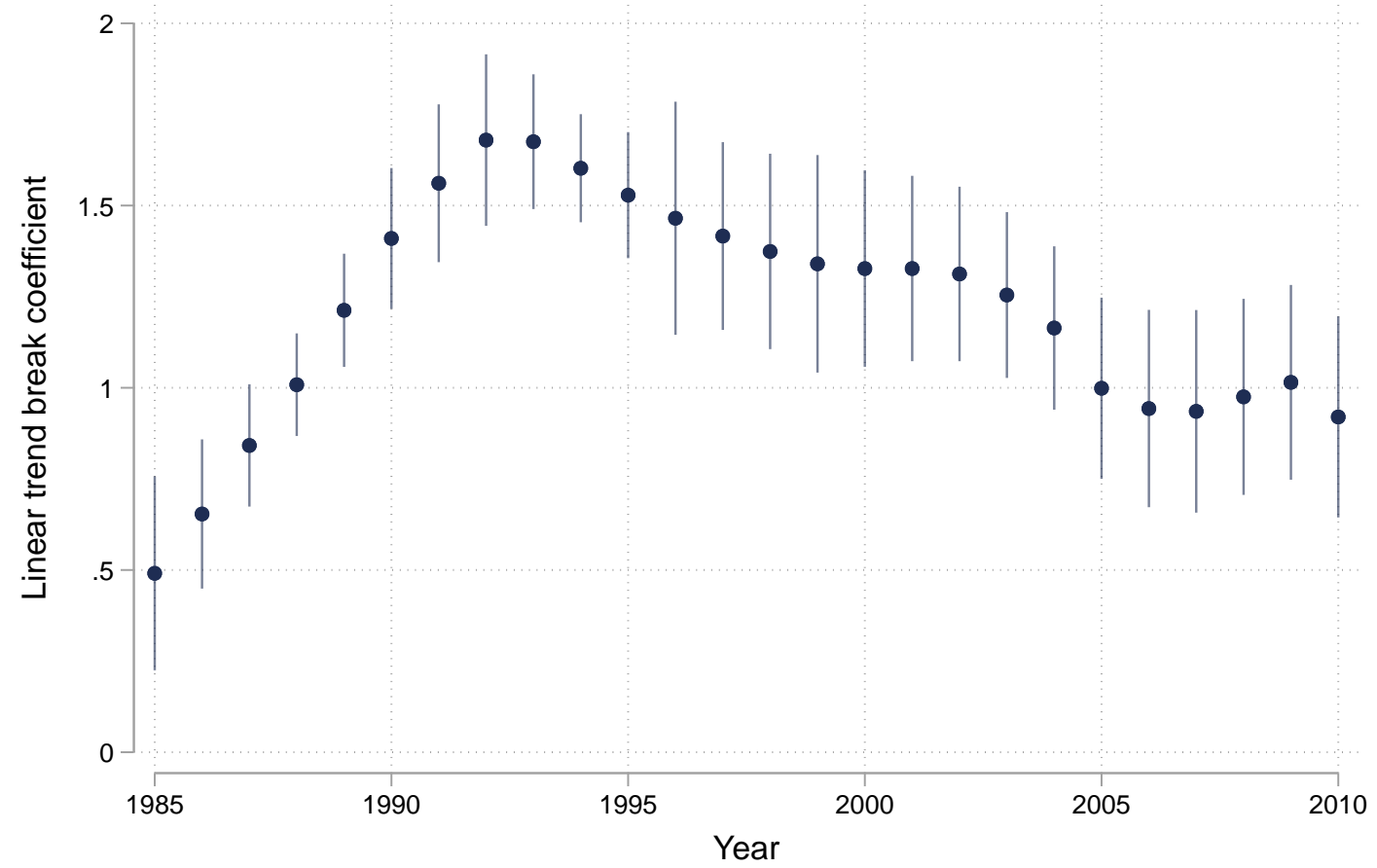

Notes: Figure shows the trend break coefficient $\kappa_{2}$ and its 95\% confidence interval from the model: $h_{t}=\kappa_{1} t+\kappa_{2} t \mathbf{1}\{t \geq \bar{t}\}+\kappa_{3} \mathbf{1}\{t \geq \bar{t}\}+\mu_{t}$, where $t$ is year, $h_{t}$ is average Mojave groundwater levels (plotted in Figure 1), and $\mu_{t}$ is an error term that is robust to serial correlation and heteroscedasticity with optimal bandwidth following (Newey and West, 1987). $\bar{t}$ is the imposed trend break which varies across years 1985-2010, shown in the x-axis. Sample period is 1980-2015, the years with continuously available average Mojave groundwater levels.

First, we return to the time series of average Mojave groundwater levels depicted in Figure 1, which shows groundwater levels stabilizing in recent decades. To examine the timing of this trend break in groundwater levels, Figure 5 plots trend break coefficients from separate regression models in which the timing of the imposed linear trend break varies across years between 1985 and 2010. We detect the largest trend break in average Mojave groundwater levels around 1993, the year in which $75 \%$ of groundwater users first adopted pumping restrictions. One concern with interpreting this trend break as causal evidence 
is that, as the theory in Section 3.2 details, groundwater levels would have also eventually stabilized had the prior open access regime continued. It is possible that stabilization under open access also would have occurred in $1993 .^{54}$

Table 7: RD effect on whether well was drilled since 1993

\begin{tabular}{lccc}
\hline & $(1)$ & $(2)$ & $(3)$ \\
& \multicolumn{3}{c}{$\begin{array}{c}\text { Outcome is whether } \\
\text { well drilled since 1993 }\end{array}$} \\
\hline$\hat{\beta}^{R D}$ & -0.188 & 0.045 & 0.049 \\
& $(0.041)$ & $(0.892)$ & $(0.402)$ \\
& {$[-.468,-.01]$} & {$[-.292, .335]$} & {$[-.087, .217]$} \\
Dist. to true boundary $(\mathrm{km})$ & 0 & -3 & 3 \\
Bandwidth & 7.400 & 5.756 & 6.947 \\
Observations & 1009 & 238 & 1828 \\
Zip codes & 26 & 23 & 31 \\
\hline
\end{tabular}

Notes: Estimates of $\beta^{R D}$ from equation (18) with a dummy variable for whether a groundwater well was built since 1993 as outcome. All models use a local linear model for $f\left(d_{i}\right)$ and exclude covariates. Column 1 uses the true adjudication boundary. Columns 2 and 3 use placebo boundaries set at 3 kilometers within the open access (i.e., $\left.d_{i}<0\right)$ and adjudication areas (i.e., $d_{i} \geq 0$ ). Point estimates use MSE-optimal bandwidth, with bandwidth reported. Inference based on robust bias-corrected standard errors, clustered at the zip code level, following Calonico, Cattaneo and Titiunik (2014). Common bandwidths employed on both sides of the threshold. Observations are uniformly weighted. $p$-values in parentheses. $95 \%$ confidence intervals in brackets.

To rule out this possibility, for our second piece of evidence we return to our spatial RD setting and look at the timing of when wells were drilled. If adjudication did not result in more groundwater compared with the open access counterfactual, one would not observe changes in efforts to access water following the introduction of adjudication. Table 7 replaces the outcome in equation (18) with a dummy variable for whether a groundwater well was drilled during or after 1993, the year when most groundwater users were first subject to pumping restrictions. The negative RD coefficient in column 1 indicates that there are more wells drilled since 1993 just inside the open access area than just inside the adjudication area. Columns 2 and 3 show that this discontinuity is not present for placebo boundaries placed 3 kilometers within the open access and adjudication areas. More wells since 1993 on the open access side is consistent with the pumping restrictions imposed by the adjudication

\footnotetext{
${ }^{54} \mathrm{~A}$ second concern may be that the Mojave Water Agency began recharging the aquifer with water imported from California's State Water Project in 1990. While this does not invalidate our RD design, which excludes changes in groundwater levels, it may prohibit one from drawing causal conclusions from the time break analysis in Figure 5. However, as Figure B.6 shows, there is no clear trend break in State Water Project imports in 1993.
} 
increasing groundwater spillovers into the open access area, lowering the cost of pumping, and increasing the returns to drilling a well on unrestricted open access parcels. ${ }^{55}$

Our final argument turns to the price of groundwater rights. Figure B.7 plots the average traded prices of perpetual rights and annual leases under the Mojave adjudication regime during the 1997-2015 period, showing consistent trading at positive prices. As discussed in Section 3.3, heterogeneous endowments produce initial differences among landowners in the shadow value of water $\lambda^{m r}$. These differences imply gains from trade, which are exhausted when $\lambda^{m r}$ is equal across all landowners and equal to the competitive price for a water right. Thus, a positive price for water implies a positive shadow value for all landowners and water use $w^{m r}$ that satisfies $\frac{\partial \pi}{\partial w}=\lambda^{m r}=p^{w}>0$. The properties of $\pi$ - concave and single-peaked in $w$ - imply $\frac{\partial \pi}{\partial w}>0$ if and only if $w^{m r}<w^{a}$ since $w^{a}$ satisfies $\frac{\partial \pi}{\partial w}=0$. The same argument holds for the price of a perpetual groundwater right. In sum, positive water prices are a sufficient condition for the adjudication to have reduced pumping relative to open access and, thereby, increased groundwater levels.

These three additional pieces of evidence all suggest that adjudication resulted in more groundwater than would have occurred under the open access counterfactual. As such, it is likely that adjudication resulted in social benefits by reducing the externality associated with groundwater pumping. Furthermore, this implies that the aggregate net benefit of adjudication calculated in Section 7.1, which omits the benefit from more groundwater, is understated.

\section{Conclusion}

This paper applies a spatial regression discontinuity design to quantify the net benefit of using an environmental market to manage a groundwater aquifer in southern California. We estimate that agricultural land values on the groundwater market side of the boundary are, on average, $220 \%$ higher than on the open access side. Using a model of dynamic groundwater extraction, we show that our RD estimate corresponds to a weak lower bound on the net benefit of the program for agricultural parcels. Heterogeneity analyses suggest that a component of these benefits comes from the tradeability of these rights, which enable a more efficient allocation of water away from water-intensive agriculture toward urban use.

\footnotetext{
${ }^{55}$ The only way for more open access wells after adjudication to not imply increased groundwater levels is if adjudication required adjudicated parcels to pump more than they would have under open access. Under this circumstance, one can construct a scenario whereby groundwater levels are lower in the adjudicated area and higher in the open access area following adjudication such that there is no change in total groundwater compared to full open access. We think this is highly unlikely, particularly since agricultural users were already pumping at their private optimum prior to adjudication such that any mandate to pump more would have led to private losses for all adjudicated users.
} 
Furthermore, additional evidence suggests that the groundwater market led to increased groundwater levels.

Our findings can inform efforts to address overextraction of other common-pool resources, such as fisheries, forests, and the global climate. For groundwater in particular, California recently passed the Sustainable Groundwater Management Act, an unprecedented policy requiring users of overextracted aquifers to adopt sustainable management plans. While it remains contentious which management tools should be employed, this paper's findings suggest that a market for groundwater rights can lead to substantial net benefits. Users and regulators alike may reference these benefits in future efforts to establish environmental markets for groundwater and common-pool resources more generally.

\section{References}

Aeschbach-Hertig, W., and Tom Gleeson. 2012. "Regional strategies for the accelerating global problem of groundwater depletion." Nature Geoscience, 5: 853-861.

Aladjem, David, and David Sunding. 2015. "Marketing the Sustainable Groundwater Management Act: Applying economics to solve California's groundwater problems." Nat. Resources ES Env't, 30: 28.

Babbitt, C., Hall M. Hayden A. Briones A.L.G. Young R., and N. Brozovic. 2017. "Groundwater Trading as a Tool or Implementing California's Sustainable Groundwater Management Act."

Baerenklau, Kenneth A, Kurt A Schwabe, and Ariel Dinar. 2014. "The residential water demand effect of increasing block rate water budgets." Land Economics, 90(4): 683-699.

Banerjee, Abhijit V, Paul J Gertler, and Maitreesh Ghatak. 2002. "Empowerment and efficiency: Tenancy reform in West Bengal." Journal of Political Economy, 110(2): 239-280.

Besley, Timothy. 1995. "Property Rights and Investment Incentives: Theory and Evidence from Ghana." Journal of Political Economy, 103(5): 903-937.

Besley, Timothy, and Robin Burgess. 2000. "Land Reform, Poverty Reduction, and Growth: Evidence from India." The Quarterly Journal of Economics, 115(2): 389-430.

Bigelow, Daniel P, Andrew J Plantinga, David J Lewis, and Christian Langpap. 2017. "How does urbanization affect water withdrawals? Insights from an econometric-based landscape simulation." Land economics, 93(3): 413-436.

Birkenbach, Anna M, David J Kaczan, and Martin D Smith. 2017. "Catch shares slow the race to fish." Nature, 544(7649): 223-226.

Calel, Raphael. 2020. "Adopt or Innovate: Understanding Technological Responses to Capand-Trade." American Economic Journal: Economic Policy, 12(3): 170-201. 
Calel, Raphael, and Antoine Dechezleprêtre. 2016. "Environmental policy and directed technological change: evidence from the European carbon market." Review of economics and statistics, 98(1): 173-191.

California Dept. of Water Res. 2015. "California's Groundwater Update 2013: A Compilation of Enhanced Content for California Water Plan Update 2013."

Calonico, Sebastian, Matias D. Cattaneo, and Max H. Farrell. 2019. "Coverage Error Optimal Confidence Intervals for Local Polynomial Regression." mimeo.

Calonico, Sebastian, Matias D Cattaneo, and Rocio Titiunik. 2014. "Robust nonparametric confidence intervals for regression-discontinuity designs." Econometrica, 82(6): 2295-2326.

Calonico, Sebastian, Matias D. Cattaneo, Max H. Farrell, and Rocío Titiunik. 2019. "Regression Discontinuity Designs Using Covariates." The Review of Economics and Statistics, forthcoming.

Cameron, A. Colin, Jonah B. Gelbach, and Douglas L. Miller. 2008. "Bootstrap-Based Improvements for Inference with Clustered Errors." The Review of Economics and Statistics, 90(3): 414-427.

Cattaneo, Matias D, Brigham R Frandsen, and Rocio Titiunik. 2015. "Randomization inference in the regression discontinuity design: An application to party advantages in the US Senate." Journal of Causal Inference, 3(1): 1-24.

Cattaneo, Matias D., Michael Jansson, and Xinwei Ma. 2019. "Simple Local Polynomial Density Estimators." Journal of the American Statistical Association, 0(0): 1-7.

Cattaneo, Matias D, Rocio Titiunik, and Gonzalo Vazquez-Bare. 2016. "Inference in regression discontinuity designs under local randomization." The Stata Journal, 16(2): 331-367.

Coase, R. H. 1960. "The Problem of Social Cost." Journal of Law and Economics, 3: pp. $1-44$.

Coman, Katharine. 1911. "Some Unsettled Problems of Irrigation." The American Economic Review, 1(1): 1-19.

Costello, Christopher, and Corbett A Grainger. 2018. "Property rights, regulatory capture, and exploitation of natural resources." Journal of the Association of Environmental and Resource Economists, 5(2): 441-479.

Costello, Christopher, Daniel Ovando, Tyler Clavelle, C. Kent Strauss, Ray Hilborn, Michael C. Melnychuk, Trevor A. Branch, Steven D. Gaines, Cody S. Szuwalski, Reniel B. Cabral, Douglas N. Rader, and Amanda Leland. 2016. "Global Fishery Prospects under Contrasting Management Regimes." Proceedings of the National Academy of Sciences, 113(18): 5125-5129.

Costello, Christopher, Nicolas Quérou, and Agnes Tomini. 2015. "Partial enclosure of the commons." Journal of Public Economics, 121: 69-78. 
Costello, Christopher, Steven D. Gaines, and John Lynham. 2008. "Can Catch Shares Prevent Fisheries Collapse?" Science, 321(5896): 1678-1681.

Covich, Alan P. 2009. "Emerging Climate Change Impacts on Freshwater Resources: A Perspective on Transformed Watersheds."

Crocker, T. 1966. "The structuring of atmospheric pollution control systems. The economics of air pollution." The economics of air pollution. New York, WW Norton \& Co, 61-86.

Cropper, Maureen L., and Wallace E. Oates. 1992. "Environmental Economics: A Survey." Journal of Economic Literature, 30(2): pp. 675-740.

Dale, John H. 1968. "Pollution, Property, and Prices: An Essay in Policy-Making."

Dalhuisen, Jasper M, Raymond JGM Florax, Henri LF De Groot, and Peter Nijkamp. 2003. "Price and income elasticities of residential water demand: a meta-analysis." Land economics, 79(2): 292-308.

Deschenes, Olivier, Michael Greenstone, and Joseph S Shapiro. 2017. "Defensive investments and the demand for air quality: Evidence from the NOx budget program." American Economic Review, 107(10): 2958-89.

Drysdale, Krystal M., and Nathan P. Hendricks. 2018. "Adaptation to an irrigation water restriction imposed through local governance." Journal of Environmental Economics and Management, 91: 150 - 165 .

Edwards, Eric C. 2016. "What lies beneath? Aquifer heterogeneity and the economics of groundwater management." Journal of the Association of Environmental and Resource Economists, 3(2): 453-491.

Elliott, Joshua, Delphine Deryng, Christoph Müller, Katja Frieler, Markus Konzmann, Dieter Gerten, Michael Glotter, Martina Flörke, Yoshihide Wada, Neil Best, Stephanie Eisner, Balázs M. Fekete, Christian Folberth, Ian Foster, Simon N. Gosling, Ingjerd Haddeland, Nikolay Khabarov, Fulco Ludwig, Yoshimitsu Masaki, Stefan Olin, Cynthia Rosenzweig, Alex C. Ruane, Yusuke Satoh, Erwin Schmid, Tobias Stacke, Qiuhong Tang, and Dominik Wisser. 2014. "Constraints and potentials of future irrigation water availability on agricultural production under climate change." Proceedings of the National Academy of Sciences, 111(9): 3239-3244.

Espey, Molly, James Espey, and W Douglass Shaw. 1997. "Price elasticity of residential demand for water: a meta-analysis." Water resources research, 33(6): 1369-1374.

Ferguson, Grant, Jennifer C McIntosh, Debra Perrone, and Scott Jasechko. 2018. "Competition for shrinking window of low salinity groundwater." Environmental Research Letters, 13(11): 114013 .

Field, Erica. 2007. "Entitled to Work: Urban Property Rights and Labor Supply in Peru." The Quarterly Journal of Economics, 122(4): 1561-1602. 
Figueroa, Teri. 2001. "Water agreement endangered: Move by Baldy Mesa Water District could lead to costly legal battles." Desert Dispatch.

Fowlie, Meredith, Stephen P Holland, and Erin T Mansur. 2012. "What do emissions markets deliver and to whom? Evidence from Southern California's NOx trading program." American Economic Review, 102(2): 965-93.

Freeman, Jody, and Charles D Kolstad. 2006. Moving to markets in environmental regulation: Lessons from twenty years of experience. Oxford University Press.

Galiani, Sebastian, and Ernesto Schargrodsky. 2010. "Property rights for the poor: Effects of land titling." Journal of Public Economics, 94(9): 700 - 729.

Gerardino, Maria Paula, Stephan Litschig, and Dina Pomeranz. 2017. "Can Audits Backfire? Evidence from Public Procurement in Chile." National Bureau of Economic Research Working Paper 23978.

Giordano, Mark. 2009. "Global Groundwater? Issues and Solutions." Annual Review of Environment and Resources, 34(1): 153-178.

Gisser, Micha, and David Sanchez. 1980. "Competition versus optimal control in groundwater pumping." Water Resources Research, 16(4): 638-642.

Gordon, H Scott. 1954. "The Economic Theory of a Common-Property Resource: The Fishery." The Journal of Political Economy, 124-142.

Goulder, Lawrence H. 2013. "Markets for pollution allowances: what are the (new) lessons?" Journal of Economic Perspectives, 27(1): 87-102.

Grafton, R. Quentin, Gary Libecap, Samuel McGlennon, Clay Landry, and Bob O'Brien. 2011. "An Integrated Assessment of Water Markets: A Cross-Country Comparison." Review of Environmental Economics and Policy, 5(2): 219-239.

Green Nylen, N., Kiparsky M. Archer K. Schnier K., and H. Doremus. 2017. "Trading Sustainably: Critical Considerations for Local Groundwater Markets Under the Sustainable Groundwater Management Act."

Hagerty, Nick. 2019. "Liquid Constrained in California: Estimating the Potential Gains from Water Markets." mimeo.

Hahn, Jinyong, Petra Todd, and Wilbert Van der Klaauw. 2001. "Identification and Estimation of Treatment Effects with a Regression-Discontinuity Design." Econometrica, 69(1): pp. 201-209.

Hahn, Robert W. 1984. "Market Power and Transferable Property Rights." The Quarterly Journal of Economics, 99(4): pp. 753-765.

Hardin, Garrett. 1968. "The Tragedy of the Commons." Science, 162(3859): 1243-1248. 
He, Yang, and Otavio Bartalotti. 2020. "Wild bootstrap for fuzzy regression discontinuity designs: obtaining robust bias-corrected confidence intervals." The Econometrics Journal. utaa002.

Hernandez-Cortes, Danae, and Kyle C Meng. 2020. "Do Environmental Markets Cause Environmental Injustice? Evidence from California's Carbon Market." National Bureau of Economic Research Working Paper 27205.

Holland, Paul W. 1986. "Statistics and Causal Inference." Journal of the American Statistical Association, 81(396): 945-960.

Hornbeck, Richard. 2010. "Barbed wire: Property rights and agricultural development." The Quarterly Journal of Economics, 125(2): 767-810.

Hsueh, Lily. 2017. "Quasi-Experimental Evidence on the "Rights to Fish": The Effects of Catch Shares on Fishermen's Days at Sea." Journal of the Association of Environmental and Resource Economists, 4(2): 407-445.

Isaksen, Elisabeth Thuestad, and Andries Richter. 2018. "Tragedy, property rights, and the commons: investigating the causal relationship from institutions to ecosystem collapse." Journal of the Association of Environmental and Resource Economics.

Iwanowsky, Mathias. 2019. "Property Rights, Resources, and Wealth: The Public Grazing Solution in the United States." mimeo.

Janmaat, Johannus A. 2005. "Sharing clams: tragedy of an incomplete commons." Journal of Environmental Economics and Management, 49(1): 26-51.

Kaffine, Daniel T, and Christopher Costello. 2011. "Unitization of spatially connected renewable resources." The BE Journal of Economic Analysis \& Policy, 11(1).

Kang, Mary, and Robert B Jackson. 2016. "Salinity of deep groundwater in California: Water quantity, quality, and protection." Proceedings of the National Academy of Sciences, 113(28): 7768-7773.

Kroetz, Kailin, James N. Sanchirico, and Daniel K. Lew. 2015. "Efficiency Costs of Social Objectives in Tradable Permit Programs." Journal of the Association of Environmental and Resource Economists, 2(3): 339-366.

Libecap, Gary D. 2011. "Institutional Path Dependence in Climate Adaptation: Coman's "Some Unsettled Problems of Irrigation"." American Economic Review, 101(1): 64-80.

Libecap, Gary D., and Dean Lueck. 2011. "The Demarcation of Land and the Role of Coordinating Property Institutions." Journal of Political Economy, 119(3): 426-467.

Lloyd, William Forster. 1833. Two Lectures on the Checks to Population. Oxford University Press.

Malik, Arun S. 1990. "Markets for pollution control when firms are noncompliant." Journal of Environmental Economics and management, 18(2): 97-106. 
Malueg, David A. 1990. "Welfare consequences of emission credit trading programs." Journal of Environmental Economics and management, 18(1): 66-77.

Mangin, Tracey, Miguel Ángel Cisneros-Mata, Jennifer Bone, Christopher Costello, Steven D Gaines, Gavin McDonald, Laura Rodriguez, C Kent Strauss, and Pedro Zapata. 2018. "The cost of management delay: The case for reforming Mexican fisheries sooner rather than later." Marine Policy, 88: 1-10.

McCrary, Justin. 2008. "Manipulation of the running variable in the regression discontinuity design: A density test." Journal of Econometrics, 142(2): 698-714.

McDonald, Robert I., Pamela Green, Deborah Balk, Balazs M. Fekete, Carmen Revenga, Megan Todd, and Mark Montgomery. 2011. "Urban growth, climate change, and freshwater availability." Proceedings of the National Academy of Sciences, 108(15): 6312-6317.

McLaughlin, David. 2020. "Well-defined property rights: Do groundwater adjudications work? Evidence from California." mimeo.

Meng, Kyle C. 2017. "Using a free permit rule to forecast the marginal abatement cost of proposed climate policy." American Economic Review, 107(3): 748-84.

Montgomery, W. David. 1972. "Markets in Licenses and Efficient Pollution Control Programs." Journal of Economic Theory, 5(3): 395 - 418.

Newey, Whitney K., and Kenneth D. West. 1987. "A Simple, Positive Semi-Definite, Heteroskedasticity and Autocorrelation Consistent Covariance Matrix." Econometrica, 55(3): 703-708.

Olmstead, Sheila M. 2010. "The economics of managing scarce water resources." Review of Environmental Economics and Policy, 4(2): 179-198.

Ostrom, Elinor. 1990. Governing the commons. Cambridge university press.

Ostrom, Elinor. 2008. "The challenge of common-pool resources." Environment: Science and Policy for Sustainable Development, 50(4): 8-21.

Palmquist, Raymond B., and Leon E. Danielson. 1989. "A Hedonic Study of the Effects of Erosion Control and Drainage on Farmland Values." American Journal of Agricultural Economics, 71(1): 55-62.

Perrone, Debra, and Scott Jasechko. 2019. "Deeper well drilling an unsustainable stopgap to groundwater depletion." Nature Sustainability, 2(8): 773-782.

Petrick, Sebastian, and Ulrich J Wagner. 2014. "The impact of carbon trading on industry: Evidence from German manufacturing firms." Available at SSRN 2389800.

Prudhomme, Christel, Ignazio Giuntoli, Emma L. Robinson, Douglas B. Clark, Nigel W. Arnell, Rutger Dankers, Balázs M. Fekete, Wietse Franssen, Dieter Gerten, Simon N. Gosling, Stefan Hagemann, David M. Hannah, Hyungjun Kim, Yoshimitsu Masaki, Yusuke Satoh, 
Tobias Stacke, Yoshihide Wada, and Dominik Wisser. 2014. "Hydrological droughts in the 21st century, hotspots and uncertainties from a global multimodel ensemble experiment." Proceedings of the National Academy of Sciences, 111(9): 3262-3267.

Rafey, Will. 2020. "Droughts, deluges, and (river) diversions: Valuing market-based water reallocation." mimeo.

Richey, Alexandra S., Brian F. Thomas, Min-Hui Lo, John T. Reager, James S. Famiglietti, Katalyn Voss, Sean Swenson, and Matthew Rodell. 2015. "Quantifying renewable groundwater stress with GRACE." Water Resources Research, 51(7): 5217-5238.

Rosen, Sherwin. 1974. "Hedonic prices and implicit markets: product differentiation in pure competition." Journal of Political Economy, 82(1): 34-55.

Salzman, James, Genevieve Bennett, Nathaniel Carroll, Allie Goldstein, and Michael Jenkins. 2018. "The Global Status and Trends of Payments for Ecosystem Services." Nature Sustainability, 1(3): 136-144.

Sampson, Gabriel S, and James N Sanchirico. 2019. "Exploitation of a mobile resource with costly cooperation." Environmental and Resource Economics, 73(4): 1135-1163.

Scheld, Andrew M., Christopher M. Anderson, and Hirotsugu Uchida. 2012. "The Economic Effects of Catch Share Management: The Rhode Island Fluke Sector Pilot Program." Marine Resource Economics, 27(3): 203-228.

Schlenker, Wolfram, W. Michael Hanemann, and Anthony C. Fisher. 2005. "Will U.S. Agriculture Really Benefit from Global Warming? Accounting for Irrigation in the Hedonic Approach." American Economic Review, 95(1): 395-406.

Schmalensee, Richard, and Robert N Stavins. 2017. "The design of environmental markets: What have we learned from experience with cap and trade?" Oxford Review of Economic Policy, 33(4): 572-588.

Shertzer, Kyle W, and Michael H Prager. 2006. "Delay in fishery management: diminished yield, longer rebuilding, and increased probability of stock collapse." ICES Journal of Marine Science, 64(1): 149-159.

Stavins, Robert N. 1995. "Transaction Costs and Tradeable Permits." Journal of Environmental Economics and Management, 29(2): 133-148.

Stavins, Robert N. 2011. "The problem of the commons: still unsettled after 100 years." American Economic Review, 101(1): 81-108.

Tietenberg, Tom. 2003. "The Tradable-Permits Approach to Protecting the Commons: Lessons for Climate Change." Oxford Review of Economic Policy, 19(3): 400-419.

Vörösmarty, Charles J., Pamela Green, Joseph Salisbury, and Richard B. Lammers. 2000. "Global Water Resources: Vulnerability from Climate Change and Population Growth." Science, 289(5477): 284-288. 
World Bank Group. 2020. "State and Trends of Carbon Pricing."

Worm, Boris, Ray Hilborn, Julia K. Baum, Trevor A. Branch, Jeremy S. Collie, Christopher Costello, Michael J. Fogarty, Elizabeth A. Fulton, Jeffrey A. Hutchings, Simon Jennings, Olaf P. Jensen, Heike K. Lotze, Pamela M. Mace, Tim R. McClanahan, Cóilín Minto, Stephen R. Palumbi, Ana M. Parma, Daniel Ricard, Andrew A. Rosenberg, Reg Watson, and Dirk Zeller. 2009. "Rebuilding Global Fisheries." Science, 325(5940): 578-585. 


\section{Appendix - For Online Publication}

\section{A Theory appendix}

Sections A.1-A.5 derives Proposition 1(a)-1(e). Section A.6 decomposes our main RD effect. Section A.8 details a back-of-the-envelope calculation for the aggregate urban net benefit.

\section{A.1 Proposition 1(a): $V^{m r}-V^{a} \gtreqless 0$}

Using equations (3) and (12), define

$$
\begin{aligned}
V^{m r}-V^{a}= & \int_{0}^{\infty}\left[\pi\left(w^{m r}(s), \bar{h}^{m r}\right)-p^{w}(s)\left(w^{m r}(s)-w^{e}(s)\right)\right] e^{-\delta s} d s \\
& -\int_{0}^{\infty} \pi\left(w^{a}(s), h^{a}(s)\right) e^{-\delta s} d s \\
& =\int_{0}^{\infty}[\underbrace{\pi\left(w^{m r}(s), \bar{h}^{m r}\right)-\pi\left(w^{a}(s), \bar{h}^{m r}\right)}_{\leq 0}+\underbrace{\pi\left(w^{a}(s), \bar{h}^{m r}\right)-\pi\left(w^{a}(s), h^{a}(s)\right)}_{\geq 0} \\
& -\underbrace{p^{w}(s)\left(w^{m r}(s)-w^{e}(s)\right)}_{\gtrless 0}] e^{-\delta s} d s
\end{aligned}
$$

where the first term in equation (A.1) is weakly negative because $w^{a}(t) \geq w^{m r}(t)$ for $t \geq 0$ and $\pi_{w}>0$. The second term in equation (A.1) is weakly positive because $\bar{h}^{m r} \geq h^{a}(t)$ for $t \geq 0$ and $\pi_{h}>0$. The third bracketed term in equation (A.1) can have either sign depending on whether the landowner is a net buyer or seller of groundwater rights. $V^{m r}-V^{a} \gtreqless 0$ follows from summing the terms in equation (A.1).

\section{A.2 Proposition 1(b): $V^{m r}-V^{m a} \gtreqless 0$}

Using equations (12) and (13), define

$$
\begin{aligned}
V^{m r}-V^{m a}= & \int_{0}^{\infty}\left[\pi\left(w^{m r}(s), \bar{h}^{m r}\right)-p^{w}(s)\left(w^{m r}(s)-w^{e}(s)\right)\right] e^{-\delta s} d s \\
& -\int_{0}^{\infty} \pi\left(w^{m a}(s), h^{m a}(s)\right) e^{-\delta s} d s \\
& =\int_{0}^{\infty}[\underbrace{\pi\left(w^{m r}(s), \bar{h}^{m r}\right)-\pi\left(w^{m a}(s), \bar{h}^{m r}\right)}_{\leq 0}+\underbrace{\pi\left(w^{m a}(s), \bar{h}^{m r}\right)-\pi\left(w^{m a}(s), h^{m a}(s)\right)}_{\geq 0} \\
& -\underbrace{p^{w}(s)\left(w^{m r}(s)-w^{e}(s)\right)}_{\gtrless 0}] e^{-\delta s} d s
\end{aligned}
$$


where the first term in equation (A.2) is weakly negative because $w^{m a} \geq w^{m r}$ for $t \geq 0$ and $\pi_{w}>0$. The second term in equation (A.2) is weakly positive because $\bar{h}^{m r} \geq h^{m a}(t)$ for $t \geq 0$ and $\pi_{h}>0$. The third bracketed term in equation (A.2) can have either sign depending on whether the landowner is a net buyer or seller of groundwater rights. $V^{m r}-V^{m a} \gtreqless 0$ follows from summing the terms in equation (A.2).

\section{A.3 Proposition 1(c): $\left(V^{m r}\left(h^{b}\right)-V^{a}\right)-\left(V^{m r}\left(h^{b}\right)-V^{m a}\left(h^{b}\right) \geq 0\right.$}

Using equations (3) and (13), define

$$
\begin{aligned}
\left(V^{m r}\left(h^{b}\right)-V^{a}\right)-\left(V^{m r}\left(h^{b}\right)-V^{m a}\left(h^{b}\right)\right. & =V^{m a}\left(h^{b}\right)-V^{a} \\
& =\int_{0}^{\infty}\left[\pi\left(w^{m a}(s), h^{b}(s)\right)-\pi\left(w^{a}(s), h^{a}(s)\right)\right] e^{-\delta s} d s \\
& =\int_{0}^{\infty}[\underbrace{\pi\left(w^{m a}(s), h^{b}(s)\right)-\pi\left(w^{a}(s), h^{b}(s)\right)}_{\geq 0} \\
& +\underbrace{\pi\left(w^{a}(s), h^{b}(s)\right)-\pi\left(w^{a}(s), h^{a}(s)\right)}_{\geq 0}] e^{-\delta s} d s \quad \text { (A.3) }
\end{aligned}
$$

where the first term in equation (A.3) is weakly positive because $w^{m a} \geq w^{a}$ for $t \geq 0$ and $\pi_{w}>0$. The second term in equation (A.3) is weakly positive because $h^{b}(t) \geq h^{a}(t)$ since $h^{m a}(t) \geq h^{a}(t)$ and $h^{b}(t) \geq h^{m a}(t)$ for $t \geq 0$ and $\pi_{h}>0$.

\section{A.4 Proposition 1(d): $\left(V^{m r}-V^{a}\right)-\left(V^{m r}\left(h^{b}\right)-V^{a}\right) \geq 0$}

Using equation (12), define

$$
\begin{aligned}
\left(V^{m r}-V^{a}\right)-\left(V^{m r}\left(h^{b}\right)-V^{a}\right) & =V^{m r}-V^{m r}\left(h^{b}\right) \\
& =\int_{0}^{\infty}\left[\pi\left(w^{m r}\left(\bar{h}^{m r}, s\right), \bar{h}^{m r}\right)-p^{w}(s)\left(w^{m r}\left(\bar{h}^{m r}, s\right)-w^{e}(s)\right)\right] e^{-\delta s} d s \\
& -\int_{0}^{\infty}\left[\pi\left(w^{m r}\left(h^{b}(s), s\right), h^{b}(s)\right)-p^{w}(s)\left(w^{m r}\left(h^{b}(s), s\right)-w^{e}(s)\right)\right] e^{-\delta s} d s \\
& =\int_{0}^{\infty} \underbrace{\left[\pi\left(w^{m r}\left(\bar{h}^{m r}, s\right), \bar{h}^{m r}\right)-\pi\left(w^{m r}\left(h^{b}(s), s\right), h^{b}(s)\right)\right]}_{\geq 0} e^{-\delta s} d s \\
& -\int_{0}^{\infty} \underbrace{p^{w}(s)\left(w^{m r}\left(\bar{h}^{m r}, s\right)-w^{m r}\left(h^{b}(s), s\right)\right)}_{\geq 0} e^{-\delta s} d s
\end{aligned}
$$

where $w^{m r}\left(\bar{h}^{m r}, s\right)$ and $w^{m r}\left(h^{b}(s), s\right)$ are the solutions to (4) given $\bar{h}^{m r}$ and $h^{b}(s)$, respectively, and a common endowment $w^{e}(s)$. The two terms in (A.4) are weakly positive because $\bar{h}^{m r} \geq h^{b}(t)$ for $t \geq 0, \pi_{h}>0, \frac{d w^{m r}}{d h}>0$ by Cramer's rule, $\pi_{w}>0$, and $p^{w}(s) \geq 0$. To show 
that the difference in the two terms,

$$
\begin{aligned}
\Omega_{0} & =\pi\left(w^{m r}\left(\bar{h}^{m r}, s\right), \bar{h}^{m r}\right)-\pi\left(w^{m r}\left(h^{b}(s), s\right), h^{b}(s)\right) \\
& -p^{w}(s)\left(w^{m r}\left(\bar{h}^{m r}, s\right)-w^{m r}\left(h^{b}(s), s\right)\right)
\end{aligned}
$$

is weakly positive, we note that $p^{w}(s)=\pi_{w}\left(w^{m r}\left(\bar{h}^{m r}, s\right), \bar{h}^{m r}\right)$, and show that the following expression is weakly positive:

$$
\begin{aligned}
\Omega_{1}= & \underbrace{\frac{\pi\left(w^{m r}\left(\bar{h}^{m r}, s\right), \bar{h}^{m r}\right)-\pi\left(w^{m r}\left(h^{b}(s), s\right), \bar{h}^{m r}\right)}{w^{m r}\left(\bar{h}^{m r}, s\right)-w^{m r}\left(h^{b}(s), s\right)}-\pi_{w}\left(w^{m r}\left(\bar{h}^{m r}, s\right), \bar{h}^{m r}\right)}_{\geq 0} \\
& +\underbrace{\frac{\pi\left(w^{m r}\left(h^{b}(s), s\right), \bar{h}^{m r}\right)-\pi\left(w^{m r}\left(h^{b}(s), s\right), h^{b}(s)\right)}{w^{m r}\left(\bar{h}^{m r}, s\right)-w^{m r}\left(h^{b}(s), s\right)}}_{\geq 0}
\end{aligned}
$$

The first term is weakly positive from the concavity of $\pi$ and the second term is weakly positive because $\bar{h}^{m r} \geq h^{b}(t)$ for $t \geq 0, \pi_{h}>0$, and $\frac{d w^{m r}}{d h}>0$. By inspection, $\Omega_{0} \geq 0 \Longleftrightarrow$ $\Omega_{1} \geq 0$. Therefore, $\left(V^{m r}-V^{a}\right)-\left(V^{m r}\left(h^{b}\right)-V^{a}\right) \geq 0$.

\section{A.5 Proposition 1(e): $\frac{d}{d t}\left(V^{m r}\left(h^{b}\right)-V^{m a}\left(h^{b}\right)\right) \gtreqless 0$}

Applying Liebnitz's Rule to equations (12) and (13) evaluated at $h^{b}$, we obtain

$$
\begin{aligned}
\frac{d}{d t}\left(V^{m r}\left(h^{b}\right)-V^{m a}\left(h^{b}\right)\right) & =\delta\left[V^{m r}\left(h^{b}\right)-V^{m a}\left(h^{b}\right)\right] \\
& +\left[\pi\left(w^{m a}(t), h^{b}(t)\right)-\pi\left(w^{m r}(t), h^{b}(t)\right)+p^{w}(t)\left(w^{m r}(t)-w^{e}(t)\right)\right]
\end{aligned}
$$

The second bracketed term is ambiguously signed. $\pi\left(w^{m a}(t), h^{b}(t)\right)-\pi\left(w^{m r}(t), h^{b}(t)\right) \geq$ 0 because $w^{m a}(t) \geq w^{m r}(t)$ for $t \geq 0$ and $\pi_{w}>0$. However, $p^{w}(t)\left(w^{m r}(t)-w^{e}(t)\right)$ is unconstrained in sign. The first bracketed term is

$$
\begin{aligned}
V^{m r}\left(h^{b}\right)-V^{m a}\left(h^{b}\right) & =\int_{t}^{\infty}[\underbrace{\pi\left(w^{m r}(s), h^{b}(s)\right)-\pi\left(w^{m a}(s), h^{b}(s)\right)}_{\leq 0}] e^{-\delta(s-t)} d s \\
& -\int_{t}^{\infty}[\underbrace{p^{w}(s)\left(w^{m r}(s)-w^{e}(s)\right)}_{\gtrless 0}] e^{-\delta(s-t)} d s
\end{aligned}
$$

This term is ambiguously signed since our model imposes no constraints on the sign of $p^{w}(s)\left(w^{m r}(s)-w^{e}(s)\right)$. Thus, $\frac{d}{d t}\left(V^{m r}\left(h^{b}\right)-V^{m a}\left(h^{b}\right)\right) \gtreqless 0$. 


\section{A.6 Decomposing $\hat{\beta}^{R D}$}

Our RD estimator from equation 16 can be written as

$$
\begin{aligned}
\hat{\beta}^{R D} & =\underset{i: d_{i}=0}{\mathbb{E}}\left[V_{i}^{m r}-V_{i}^{m a}\right] \\
& =\underset{i: d_{i}=0}{\mathbb{E}}\left[\int_{0}^{\infty}\left[\pi\left(w_{i}^{m r}(s), h_{i}(s)\right)-p^{w}(s)\left(w_{i}^{m r}(s)-w_{i}^{e}(s)\right)-\pi\left(w_{i}^{m a}(s), h_{i}(s)\right)\right] e^{-\delta s} d s\right] \\
& =\underset{i: d_{i}=0}{\mathbb{E}}\left[\int_{0}^{\infty}[\underbrace{\pi\left(w_{i}^{e}(s), h_{i}(s)\right)-\pi\left(w_{i}^{m a}(s), h_{i}(s)\right)}_{\leq 0}] e^{-\delta s} d s\right] \\
& +\underset{i: d_{i}=0}{\mathbb{E}}\left[\int_{0}^{\infty}[\underbrace{\pi\left(w_{i}^{m r}(s), h_{i}(s)\right)-\pi\left(w_{i}^{e}(s), h_{i}(s)\right)-p^{w}(s)\left(w_{i}^{m r}(s)-w_{i}^{e}(s)\right)}_{\geq 0}] e^{-\delta s} d s\right]
\end{aligned}
$$

where the first equality applies equations (12) and (13) for parcels at the boundary. The second equality adds and subtracts profit under initial water endowment for parcels with property rights, or $\pi\left(w_{i}^{e}(s), h_{i}(s)\right)$. The first bracketed term, which captures the restriction cost, is weakly negative because for $h_{i}(t), \pi\left(w, h_{i}(t)\right)$ is maximized at $w^{m a}\left(h_{i}(t)\right)$.

We examine the second bracketed term, reflecting the gains from groundwater permit trading, separately for net permit buyers and sellers, and for each time period, thus dropping the time subscript. Observe that profit maximization under adjudication implies $\pi_{w}=p^{w}$. For a net permit buyer with $w_{i}^{m r} \geq w_{i}^{e}$, note that

$$
\pi\left(w_{i}^{m r}, h_{i}\right)-\pi\left(w_{i}^{e}, h_{i}\right)-p^{w}(s)\left(w_{i}^{m r}-w_{i}^{e}\right) \geq 0 \Longleftrightarrow \frac{\pi\left(w_{i}^{m r}, h_{i}\right)-\pi\left(w_{i}^{e}, h_{i}\right)}{w_{i}^{m r}-w_{i}^{e}} \geq \pi_{w}\left(w_{i}^{m r}\right)
$$

This inequality holds because $\pi$ is concave in w. For a net permit seller, with $w_{i}^{m r} \leq w_{i}^{e}$

$$
\pi\left(w_{i}^{m r}, h_{i}\right)-\pi\left(w_{i}^{e}, h_{i}\right)-p^{w}(s)\left(w_{i}^{m r}-w_{i}^{e}\right) \geq 0 \Longleftrightarrow \frac{\pi\left(w_{i}^{m r}, h_{i}\right)-\pi\left(w_{i}^{e}, h_{i}\right)}{w_{i}^{m r}-w_{i}^{e}} \leq \pi_{w}\left(w_{i}^{m r}\right)
$$

which holds again because $\pi$ is concave in $\mathrm{w}$.

\section{A.7 Calculating value of groundwater rights for adjudicated parcels in RD sample}

Taking the definition of the RD effect on land values (in levels) from equation (17), we can write the following inequality: 


$$
\begin{aligned}
\hat{\beta}^{R D} & \leq \underset{i: d_{i}=0}{\mathbb{E}}\left[\int_{0}^{\infty} p^{w}(s) w_{i}^{e}(s) e^{-\delta s} d s\right] \\
& =\underset{i: d_{i}=0}{\mathbb{E}}[\underbrace{w_{i}^{e}(0)}_{\begin{array}{c}
\text { endowed } \\
\text { perpetual right }
\end{array}} \underbrace{\int_{0}^{\infty} p^{w}(s) e^{-(\omega+\delta) s} d s}_{\begin{array}{c}
\text { price of } \\
\text { perpetual right }
\end{array}}]
\end{aligned}
$$

where the inequality in the first line follows because the expression on the right-hand side is part of the gains from trade component of $\hat{\beta}^{R D}$ (see equation (17)) and because both this expression and the gains from trade are weakly positive. The second line applies the relationship $w_{i}(s)=w_{i}(0) e^{-\omega s}$ whereby an annual water right lease, $w_{i}(s)$, is defined as a perpetual water right scaled each year at rate $\omega$, the rampdown in allowable aggregate pumping. The second line captures the value of endowed groundwater rights for adjudicated parcels in our RD sample. We obtain the number of endowed perpetual rights at the parcel level and average price of perpetual rights in 2015 from the Mojave Water Agency.

\section{A.8 Calculating the aggregate net benefit for urban areas}

Water for urban areas is not extracted on site but rather available through municipal water systems. As such, we are unable to apply our spatial RD approach for urban areas within the adjudication regime. In this section, we extend our theory to inform a back-of-the-envelope calculation on the aggregate net benefit of adjudication to urban areas.

To do so, we make two simplifying assumptions. First, as with our RD design on agricultural parcels, we omit increases in groundwater levels as a consequence of adjudication, implying, as with our RD estimate, that this calculation is a weak lower bound on the true effect. Second, we assume that under adjudication the system has reached a steady state where urban pumping, $w^{*}$, and the annual price of groundwater, $\bar{p}^{w}$, are constant over time. Let $\Pi_{w}(w)$ be the instantaneous aggregate urban groundwater demand. ${ }^{56}$ Unlike agricultural users, who under open access pumped until the marginal value of water is zero, municipalities providing water to urban areas faced constraints on pumping prior to adjudication because they had groundwater access that was "junior" to agricultural landowners. As a consequence, municipalities were likely pumping below their private optimum prior to adjudication. If aggregate urban consumption increases following adjudication, there would be an aggregate urban net benefit provided that the gain from increased water use offsets the cost of purchasing groundwater rights to enable that increased consumption.

Let $w^{a}$ denote the steady-state pumping by urban areas under the open access counterfactual and $w^{e}$ denote the steady-state groundwater endowment under adjudication. $w^{e}<w^{a}$ in order to stabilize groundwater levels. The pumping restriction under adjudication imposes

\footnotetext{
${ }^{56}$ The urban profit function $\Pi(\cdot)$ is analogous to an agricultural user's profits, $\pi(\cdot)$, from Section 3 , but differs in that profit is not defined per unit area of land, but rather for the aggregate population of households and businesses served by municipal water systems.
} 
a loss in perpetuity to urban areas given by:

$$
L=\int_{w^{e}}^{w^{a}} \frac{1}{\delta} \Pi_{w}(w) d w
$$

where $\delta$ is the discount rate. Adjudication also allowed cities to buy and sell water rights. When a municipality buys perpetual rights to increase water consumption, its gain is:

$$
G=\int_{w^{e}}^{w^{*}} \frac{1}{\delta} \Pi_{w}(w) d w-r\left(w^{*}-w^{e}\right)
$$

where $w^{*}$ is the post-trade consumption of water in perpetuity defined by $\Pi_{w}\left(w^{*}\right)=\bar{p}^{w}$ and $r$ is the value of a perpetual right defined by $r=\frac{1}{\delta} \Pi_{w}\left(w^{*}\right)$. If urban areas decrease water consumption following adjudication, $w^{*}<w^{a}$, then they are unambiguously worse off since

$$
G-L=-\int_{w^{*}}^{w^{a}} \frac{1}{\delta} \Pi_{w}(w) d w-r\left(w^{*}-w^{e}\right)<0
$$

However, if urban areas increase water consumption following adjudication, $w^{*}>w^{a}$, the net benefit from adjudication can be negative or positive

$$
G-L=\int_{w^{a}}^{w^{*}} \frac{1}{\delta} \Pi_{w}(w) d w-r\left(w^{*}-w^{e}\right) \gtreqless 0
$$

Table A.1 calculates the aggregate net benefit to urban areas in 2015. From the Mojave Water Agency, we obtain aggregate endowment of groundwater rights for municipalities $\left(w^{e}\right)$ and aggregate urban groundwater use $\left(w^{*}\right)$ as the sum of endowments and net transfers. For aggregate urban groundwater use under the counterfactual open access regime $\left(w^{a}\right)$, we conservatively assume that aggregate average annual urban groundwater use in 1986-1990, prior to adjudication, would be maintained by 2015 had adjudication not been established. ${ }^{57}$ Using instantaneous residential demand elasticities between -0.4 and -0.7 (Espey, Espey and Shaw, 1997; Dalhuisen et al., 2003; Olmstead, 2010; Baerenklau, Schwabe and Dinar, 2014), we calculate an aggregate net benefit to urban areas of $\$ 72-131$ million (in 2015 dollars).

Table A.1: Calculating the aggregate urban net benefit

\begin{tabular}{ccccccc}
\hline$w^{e}$ & $w^{a}$ & $w^{*}$ & $\mathrm{r}$ & \multicolumn{2}{c}{ Inst. demand elasticity: } \\
\hline 60191 & 64327 & 83927 & 1725 & -0.4 & -0.6 & -0.7
\end{tabular}

Aggregate urban net benefit (in mil. 2015 \$USD)

$$
\begin{array}{lll}
71.8 & 111.3 \quad 131.0
\end{array}
$$

Notes: Total urban endowment of groundwater rights $\left(w^{e}\right)$, groundwater consumption $\left(w^{*}\right)$, and average price of a perpetual right $(r)$ for 2015. Restricted aggregate urban water use under the open access counterfactual $\left(w^{a}\right)$ is assumed equal to average 1986-1990 aggregate urban groundwater use. Instantaneous elasticities for residential urban demand of -0.4, -.6, and -.7 from Espey, Espey and Shaw (1997); Dalhuisen et al. (2003); Olmstead (2010); Baerenklau, Schwabe and Dinar (2014). Discount rate set at $\delta=0.02$.

\footnotetext{
${ }^{57}$ In practice, the true counterfactual $w^{a}$ should be lower as groundwater levels deplete under open access conditions, implying a larger gain from rights trading.
} 


\section{B Appendix Figures}

Figure B.1: Agricultural revenue before and after adjudication

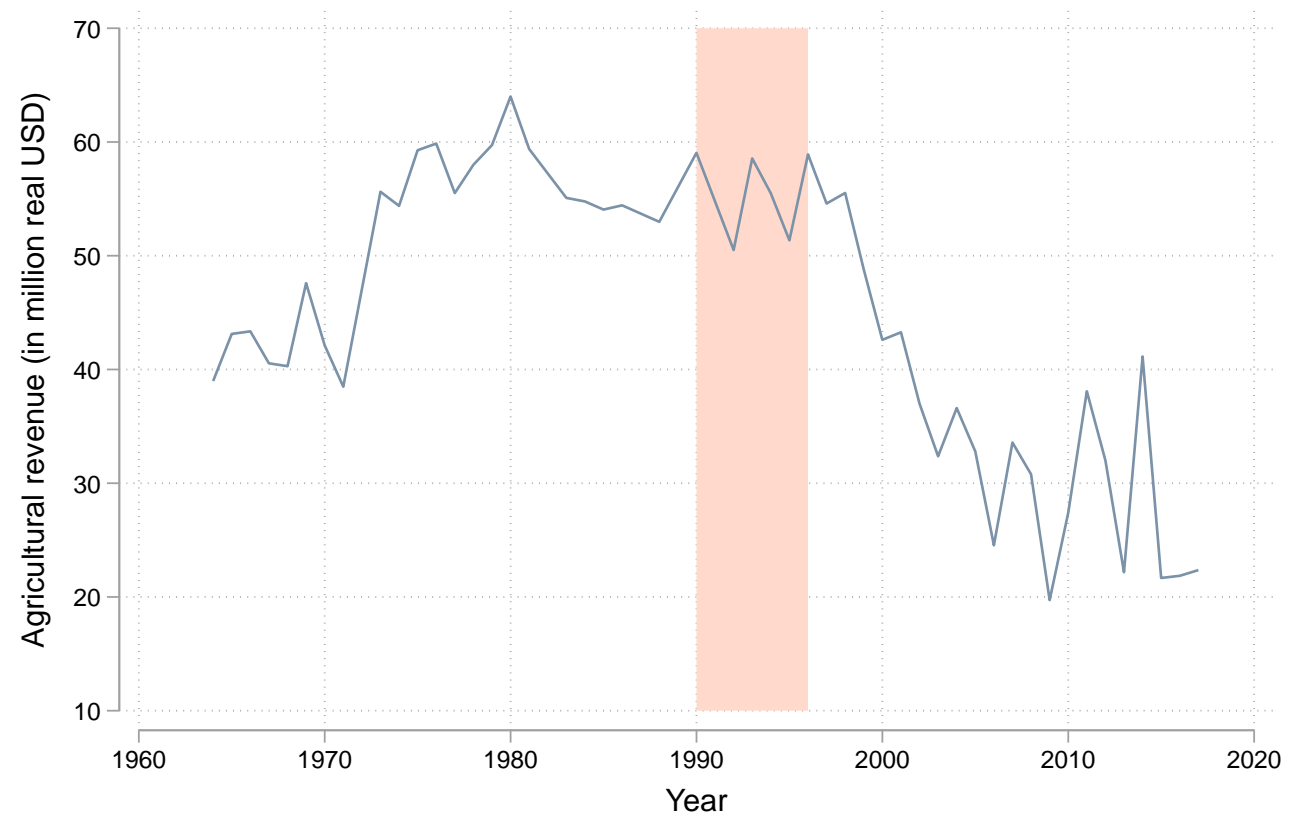

Notes: Plot shows agricultural revenue (in real million USD) for the Mojave Desert from 1960-2017. Data takes the sum of revenue from the North and South Desert regions of San Bernardino county, obtained from the San Bernardino county Annual Crop Reports. Orange-shaded area marks the period from 1990 when the initial adjudication lawsuit was filed to 1996 when the final adjudication court ruling was issued. 


\section{Figure B.2: Graphical RD: covariates}
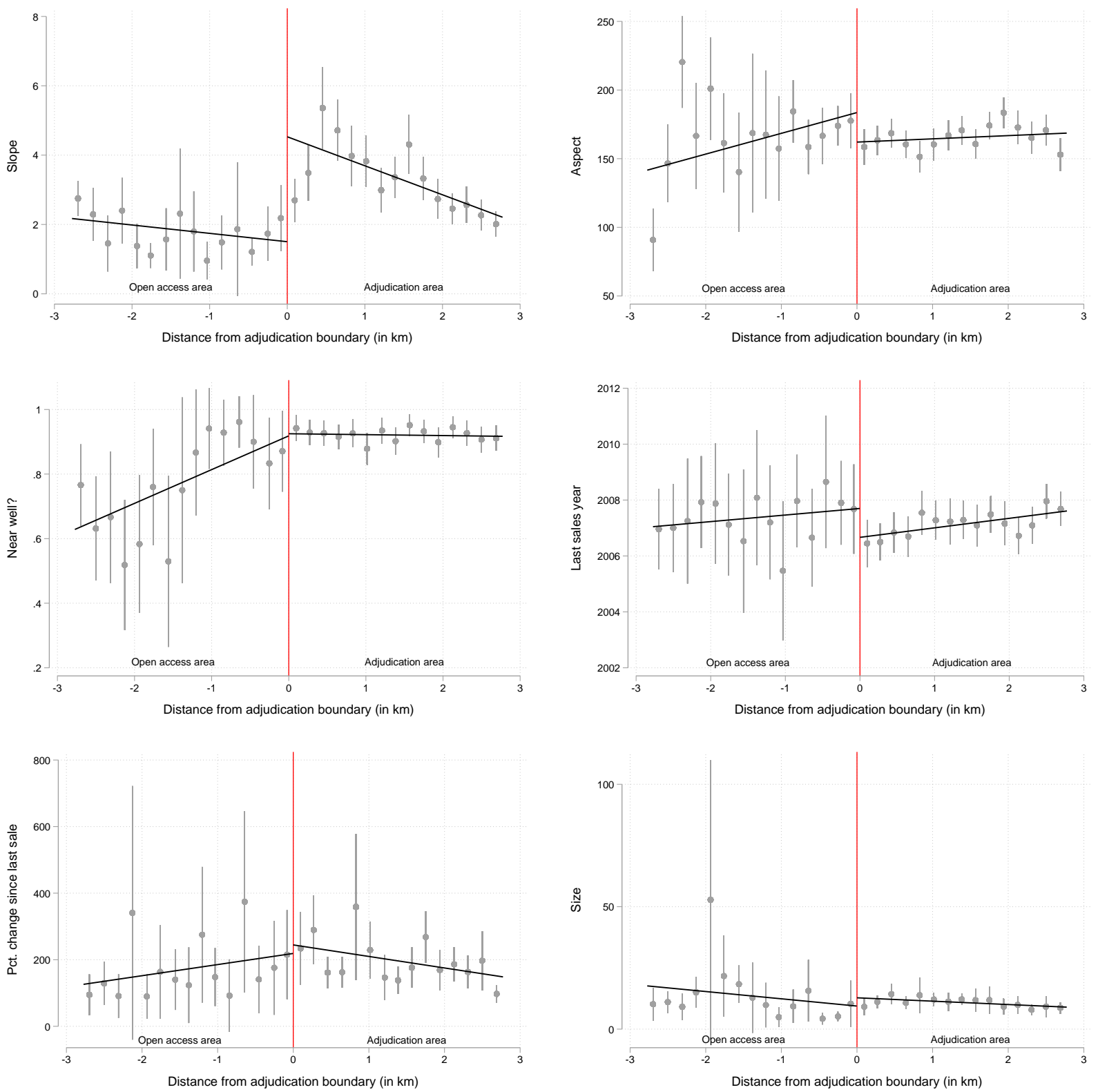

Notes: Vertical axes shows covariate value. Horizontal axes shows normalized distance in kilometers, $d_{i}$, to property rights boundary with $d_{i} \geq 0$ indicating the adjudication area and $d_{i}<0$ indicating the open access area. Mean and 95\% confidence intervals shown for the outcome within equally-spaced distance bins. Solid lines show linear functions fitted over unbinned data, separately for each side of the boundary. 
Figure B.3: Graphical RD: global effect

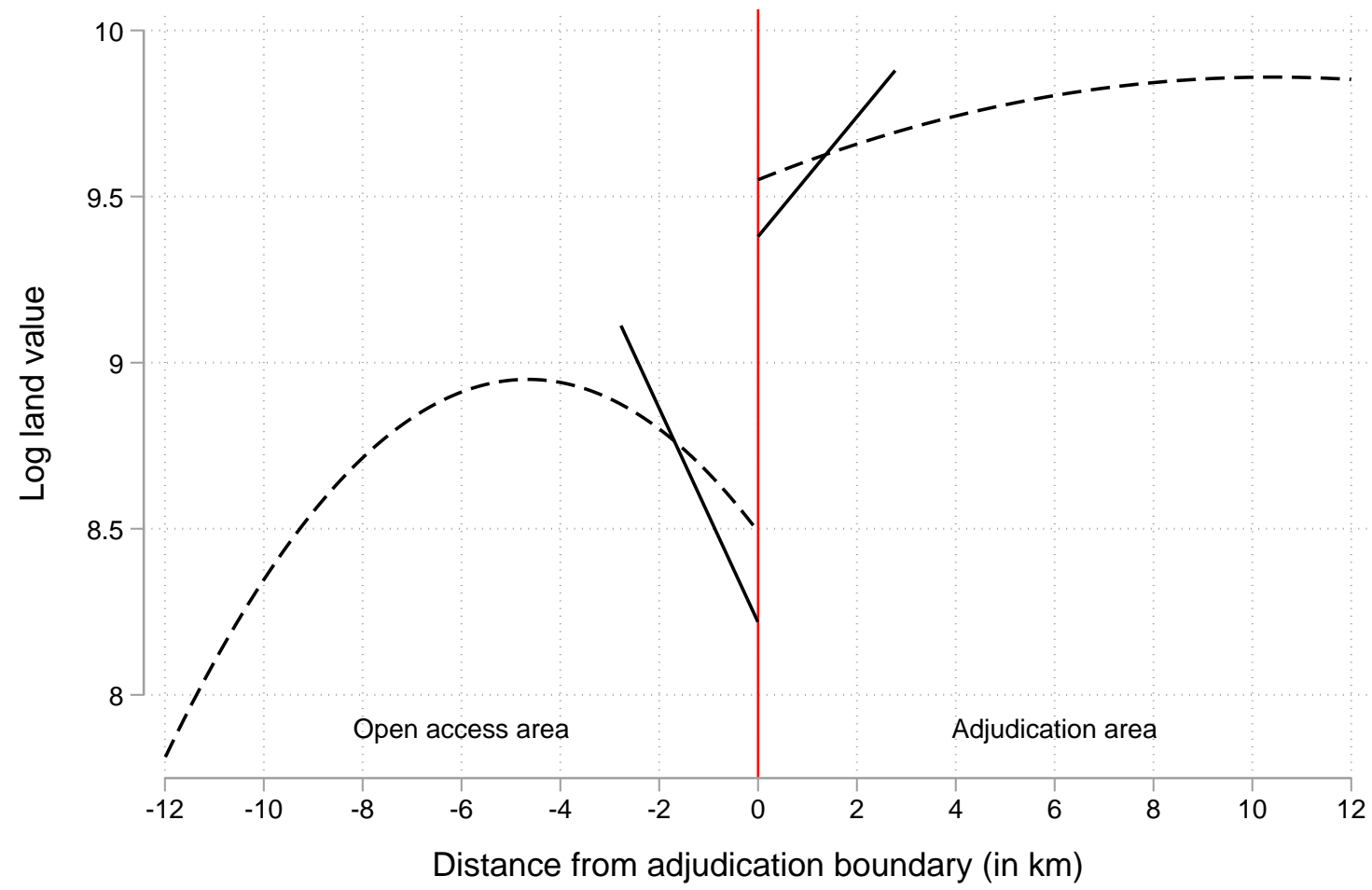

Notes: Vertical axes shows log land value. Horizontal axes shows normalized distance in kilometers, $d_{i}$, to adjudication boundary with $d_{i} \geq 0$ indicating the adjudication area and $d_{i}<0$ indicating the open access area. Solid lines show local linear functions fitted separately for each side of the boundary within the MSE-optimal bandwidth shown in column 1 of Table 2. Dashed lines show global quadratic functions fitted separately for each side of the boundary. 
Figure B.4: Graphical RD: land value before adjudication (1976-1979)

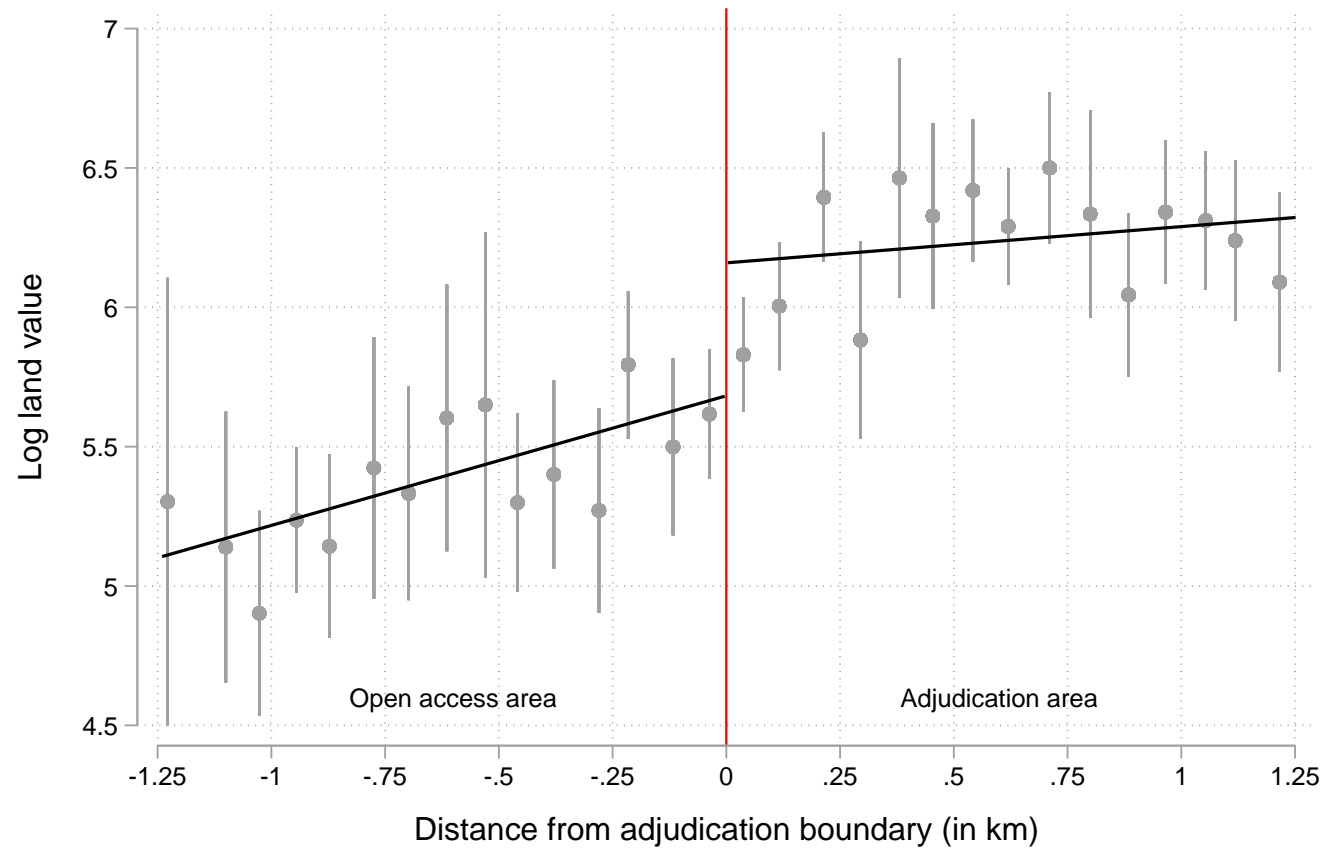

Notes: Vertical axes shows log land value during 1976-1979. Horizontal axes shows normalized distance in kilometers, $d_{i}$, to property rights boundary with $d_{i} \geq 0$ indicating property rights area and $d_{i}<0$ indicating open access area. Mean and 95\% confidence intervals shown for the outcome within equally-spaced distance bins. Solid lines show linear functions fitted over unbinned data, separately for each side of the boundary.

Figure B.5: Heterogeneity: south to north

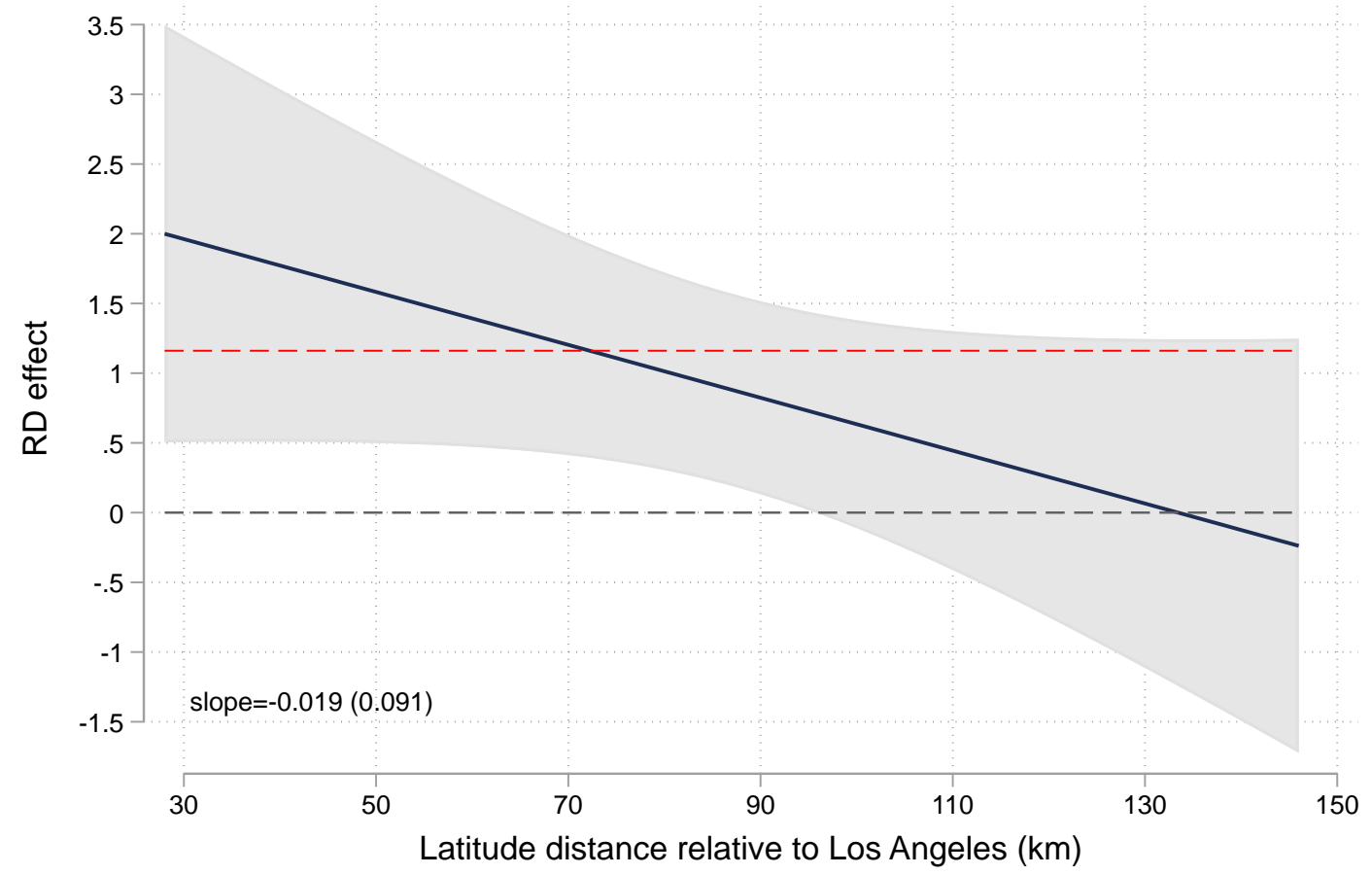

Notes: Plot shows heterogeneity in $\hat{\beta}^{R D}$ as a function of a parcel's latitude, relative to the centroid of Los Angeles. Point estimate and standard error on slope shown. Horizontal red dashed line shows baseline uninteracted RD effect from column 1 of Table 2. 95\% confidence intervals shown. 
Figure B.6: Annual transfers from the State Water Project into the Mojave Aquifer

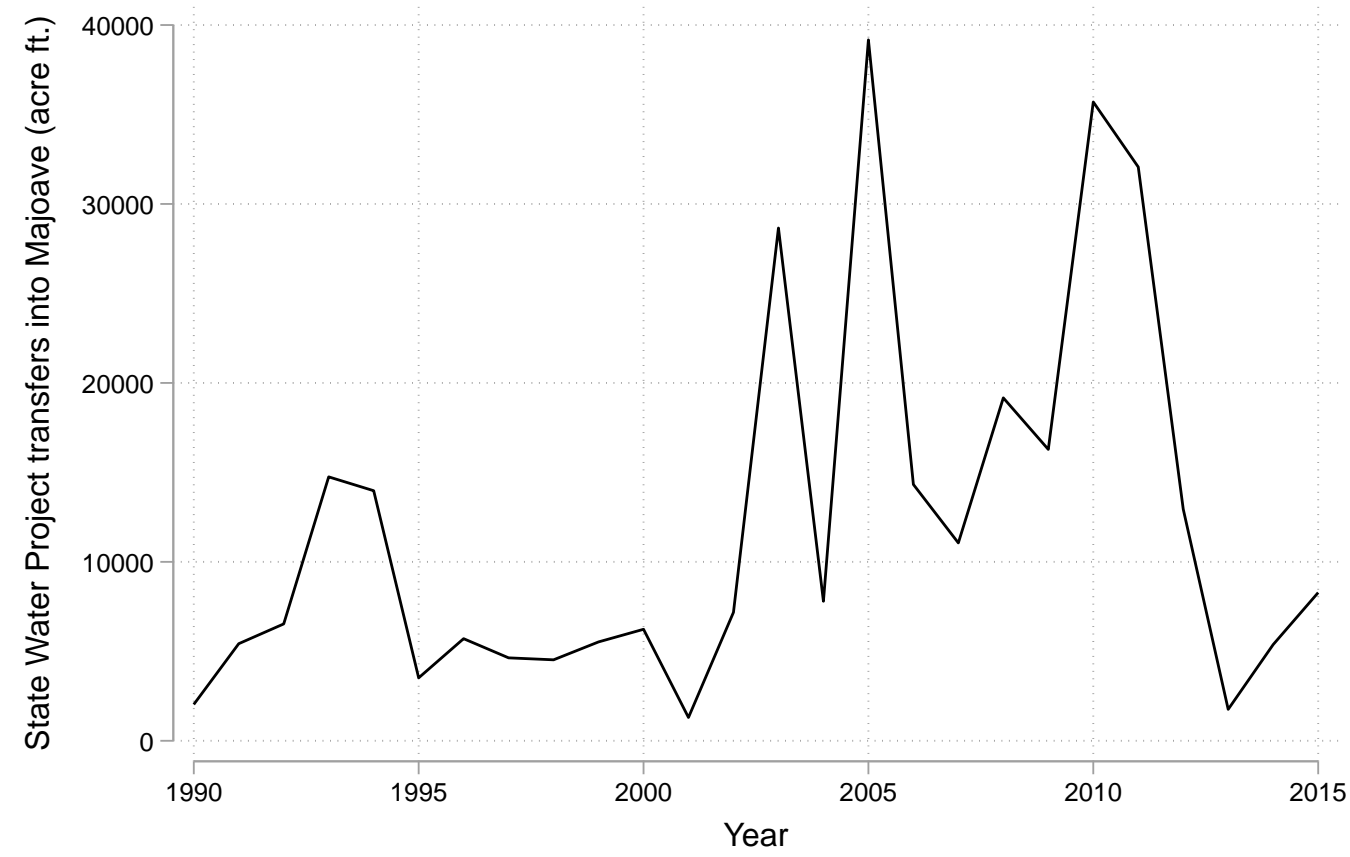

Notes: Figure shows annual transfers from the State Water Project to the Mojave Aquifer. Data from the Mojave Water Agency.

Figure B.7: Average price and total trading volume of annual groundwater permits

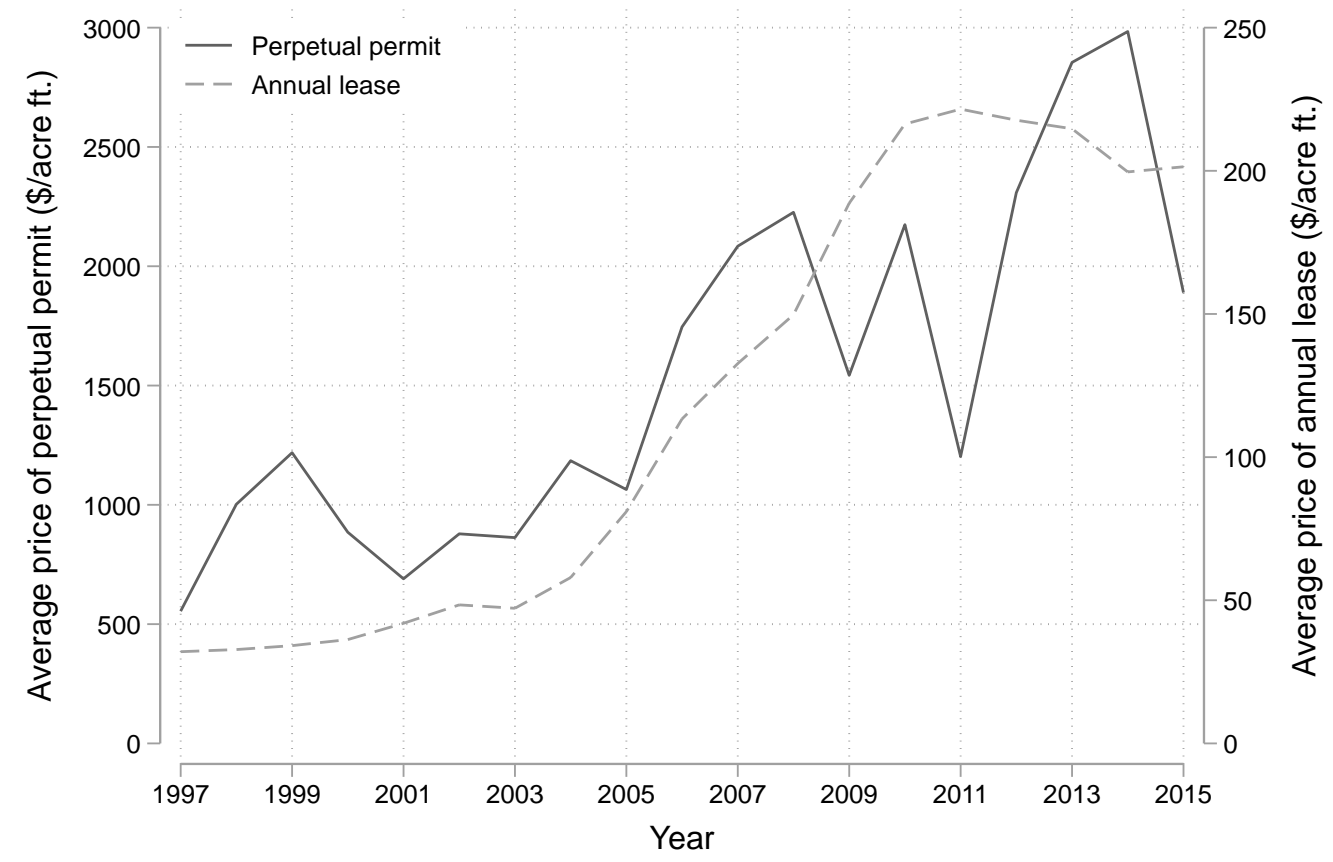

Notes: Average price of a perpetual permit and annual lease between 1997-2015. Data from the Mojave Water Agency. 


\section{Appendix Tables}

Table C.1: Summary statistics

\begin{tabular}{lccccc}
\hline & Obs & Mean & Std dev & $\mathrm{p}(1)$ & $\mathrm{p}(99)$ \\
\hline & & & & & \\
Land value (in 2015 USD) & 36698 & 24896.1 & 54614.1 & 468.0 & 225119.0 \\
Dist. from prop. rights boundary (in km) & 36698 & 11.9 & 11.1 & -14.9 & 37.6 \\
Avg. slope (in degrees) & 36698 & 1.9 & 2.6 & 0.1 & 14.5 \\
Avg. aspect (in compass direction) & 36671 & 166.5 & 93.7 & 12.9 & 345.0 \\
Dummy whether near 1 mile of well & 36698 & 0.9 & 0.3 & 0.0 & 1.0 \\
Parcel size (in acres) & 36698 & 12.9 & 36.0 & 0.2 & 157.9 \\
Last sales year & 36698 & 1996.8 & 14.5 & 1968.0 & 2015.0 \\
Land value change since last sale (in \%) & 36661 & 266.7 & 3018.2 & -73.4 & 1809.1 \\
\hline
\end{tabular}

NotEs: Number of observations, mean, standard deviation, 1st percentile and 99th percentile of variables in primary dataset (see Section 5). Sample includes land parcels close to the adjudication boundary used in RD estimation and those farther away. 


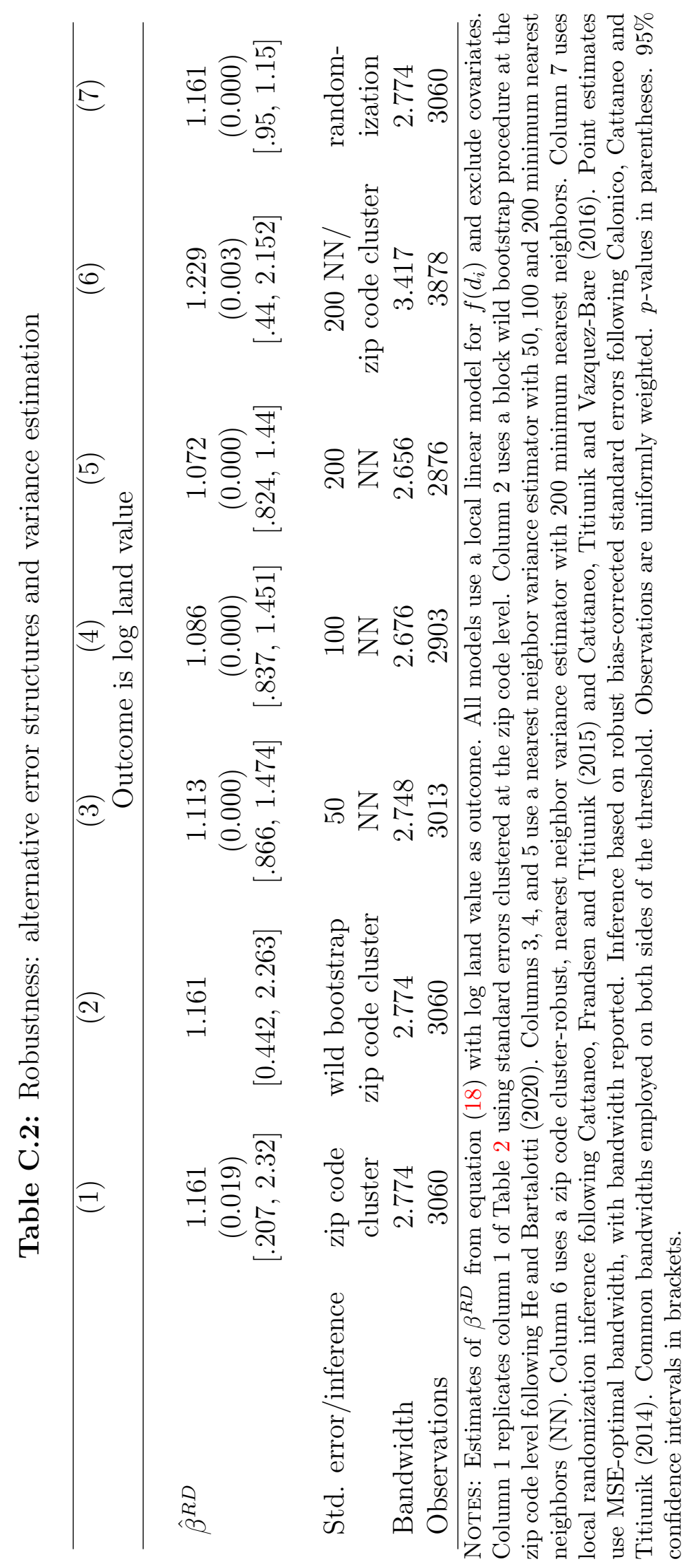


Table C.3: Robustness: bandwidth selection procedures

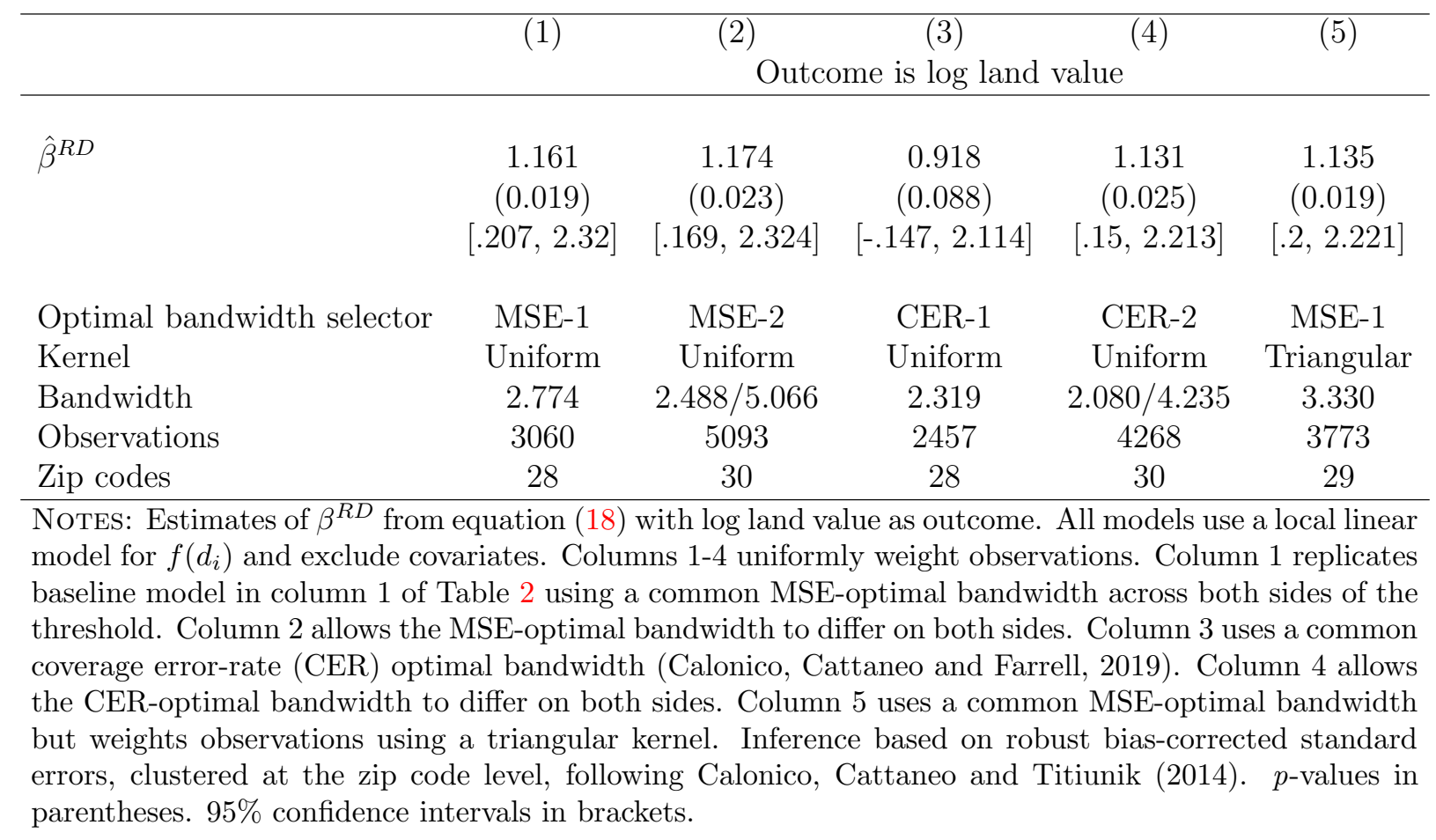

